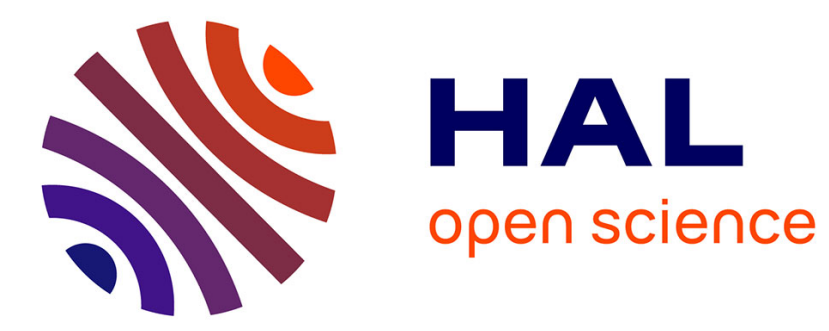

\title{
Framework for submodel improvement in wildfire modeling
}

Mohamad El Houssami, Aymeric Lamorlette, Dominique Morvan, Rory M Hadden, Albert Simeoni

\section{- To cite this version:}

Mohamad El Houssami, Aymeric Lamorlette, Dominique Morvan, Rory M Hadden, Albert Simeoni. Framework for submodel improvement in wildfire modeling. Combustion and Flame, 2018, 190, pp.1224. 10.1016/j.combustflame.2017.09.038 . hal-02114000

\section{HAL Id: hal-02114000 https://hal-amu.archives-ouvertes.fr/hal-02114000}

Submitted on 29 Apr 2019

HAL is a multi-disciplinary open access archive for the deposit and dissemination of scientific research documents, whether they are published or not. The documents may come from teaching and research institutions in France or abroad, or from public or private research centers.
L'archive ouverte pluridisciplinaire HAL, est destinée au dépôt et à la diffusion de documents scientifiques de niveau recherche, publiés ou non, émanant des établissements d'enseignement et de recherche français ou étrangers, des laboratoires publics ou privés. 


\title{
Framework for submodel improvement in wildfire modeling
}

\author{
Mohamad El Houssami ${ }^{\mathrm{a}}$, Aymeric Lamorlette ${ }^{\mathrm{b}}$, Dominique Morvan ${ }^{\mathrm{c}}$, Rory M. Hadden ${ }^{\mathrm{a}}$, \\ Albert Simeonic,** \\ a The University of Edinburgh, Edinburgh EH9 3JL, UK \\ ${ }^{\mathrm{b}}$ Aix-Marseille Université, CNRS, CentMarseille, M2P2, 13451 Marseille, France \\ ${ }^{c}$ Worcester Polytechnic Institute, 100 Institute Road, Worcester, MA 01609, USA
}

\section{A R T I C L E I N F O}

\section{Keywords:}

Multiphase

Forced flow

Porous

LES

\begin{abstract}
A B S T R A C T
An experimental and numerical study was carried out to assess the performance of the different submodels and parameters used to describe the burning dynamics of wildfires. A multiphase formulation was used and compared to static fires of dried pitch pine needles of different bulk densities. The samples were exposed to an external heat flux of $50 \mathrm{~kW} / \mathrm{m}^{2}$ in the FM Global Fire Propagation Apparatus and subjected to different airflows, providing a controlled environment and repeatable conditions. Submodels for convective heat transfer, drag forces, and char combustion were investigated to provide mass loss rate, flaming duration, and gas emissions. Good agreement of predicted mass loss rates and heat release rates was achieved, where all these submodels were selected to suit the tested conditions. Simulated flaming times for different flow conditions and different fuel bulk densities compared favorably against experimental measurements. The calculation of the drag forces and the heat transfer coefficient was demonstrated to influence greatly the heating/cooling rate, the degradation rate, and the flaming time. The simulated $\mathrm{CO}$ and $\mathrm{CO}_{2}$ values compared well with experimental data, especially for reproducing the transition between flaming and smoldering. This study complements a previous study made with no flow to propose a systematic approach that can be used to assess the performance of the submodels and to better understand how specific physical phenomena contribute to the wildfire dynamics. Furthermore, this study underlined the importance of selecting relevant submodels and the necessity of introducing relevant subgrid-scale modelling for larger scale simulations.
\end{abstract}

\section{Introduction}

Understanding the burning behavior of wildland fuels is essential to develop a complete understanding of wildfire spread. For the last decades, numerous studies have been attempted to better describe the fire dynamics of solid fuels [1-3], including polymers [4-8], cellulosic materials [9,10], and different species of wood [1114]. The transfer of this knowledge to describe the burning behavior of wildland fuels, which are natural polymers, is not trivial because they differ from classical solid fuels, as they often consist in highly porous media where the solid phase is very small compared to the gas phase. The main challenge arises from the porous nature of the fuels and its coupling with the transient surrounding environment, which strongly influences the heat transfer, degradation rates, and the burning dynamics [15]. Indeed, during combustion of a highly porous bed, the heat captured by the solid

\footnotetext{
* Corresponding author.

E-mail address: asimeoni@wpi.edu (A. Simeoni).
}

phase is a result of the energy balance from the flame feedback by radiation and from the fresh air entrained into the fuel layer by convection, but also reacting with the pyrolysis products and with the char residue. As a consequence, these homogeneous and heterogeneous combustions contribute to transfer energy to the solid phase. This behavior is different from that observed for solid fuels for which the radiative and convective contributions of the flame can be considered to be transferred into the solid by conduction [16]. This highly porous configuration is typically found in pine needle beds, which are often found on the forest floors. They can typically be found accumulated near structures in the Wildland Urban Interface (WUI), increasing the fire risk [17]. As the need to understand the burning dynamics of wildland fuels is a matter of great urgency in order to improve wildfire assessment tools, many studies have been performed over the last decades. Among those, Dimitrakopoulos and Papaioannou [18] used the cone colorimeter to determine the ignition time and the flammability of typical Mediterranean forest fuels and proposed four flammability classes. Schemel et al. [19] reported a calorimetric study of pine needle beds using the FM Global Fire Propagation Apparatus (FPA), during 


\begin{tabular}{|c|c|c|}
\hline \multicolumn{3}{|c|}{ Nomenclature } \\
\hline $\mathrm{C}$ & \multicolumn{2}{|c|}{ Convective heat transfer constants } \\
\hline$C_{D}$ & \multicolumn{2}{|c|}{ Drag force coefficient } \\
\hline$D$ & \multicolumn{2}{|c|}{ Equivalent diameter } \\
\hline$E_{C H A R}$ & \multicolumn{2}{|c|}{ Energy activation for char oxidation } \\
\hline HRR & \multicolumn{2}{|c|}{ Average Heat Release Rate } \\
\hline$k$ & \multicolumn{2}{|c|}{ Air thermal conductivity } \\
\hline$K_{\text {CHAR }}$ & \multicolumn{2}{|c|}{ pre-exponential coefficient for char oxidation } \\
\hline$m_{0}$ & \multicolumn{2}{|c|}{ Initial mass } \\
\hline$m, n$ & \multicolumn{2}{|c|}{ Convective heat transfer coefficient constants } \\
\hline $\mathrm{Nu}$ & \multicolumn{2}{|c|}{ Nusselt number } \\
\hline$P$ & \multicolumn{2}{|c|}{ Pressure } \\
\hline $\operatorname{Pr}$ & \multicolumn{2}{|c|}{ Prandtl number } \\
\hline$Q_{\text {char }}^{(s)}$ & \multicolumn{2}{|c|}{ Char oxidation source term } \\
\hline$Q_{\text {CONV }}^{(S)}$ & \multicolumn{2}{|c|}{ Convective heat transfer source term } \\
\hline & \multicolumn{2}{|c|}{ Ideal gas constant } \\
\hline $\operatorname{Re}$ & \multicolumn{2}{|c|}{ Reynolds number } \\
\hline$T, T_{\mathrm{S}}$ & \multicolumn{2}{|c|}{ Gas and solid phase temperatures } \\
\hline & \multicolumn{2}{|c|}{ Velocity } \\
\hline$Y_{\mathrm{O}_{2}}$ & \multicolumn{2}{|c|}{ Oxygen mass fraction } \\
\hline \multicolumn{3}{|c|}{ Greek symbols } \\
\hline \multicolumn{2}{|c|}{$\alpha_{\mathrm{g}}, \alpha_{\mathrm{s}}$} & Volume fraction of gas and solid phases \\
\hline \multicolumn{2}{|c|}{$\Delta h_{\mathrm{CO}}, \Delta h_{\mathrm{CO}_{2}}$} & Heat of combustion of $\mathrm{CO}$ and $\mathrm{CO}_{2}$ \\
\hline \multicolumn{2}{|c|}{$\rho$} & Gas density \\
\hline \multicolumn{2}{|l|}{$\sigma_{s}$} & Surface to volume ratio \\
\hline & Split function \\
\hline \multicolumn{2}{|c|}{$\varphi_{\text {char }}^{(S)}, \varphi_{D R Y}^{(S)}, \varphi_{\mathrm{H}_{2} \mathrm{O}}^{(S)}$} & $\begin{array}{l}\text { Mass fraction of char, dry pine and wa- } \\
\text { ter in solid phase }\end{array}$ \\
\hline \multirow{2}{*}{\multicolumn{2}{|c|}{$\dot{\omega}_{c h a r}^{\prime \prime \prime}, \dot{\omega}_{p y r}^{\prime \prime \prime}, \dot{\omega}_{v a p}^{\prime \prime \prime}$}} & Convective heat transfer coefficient \\
\hline & & $\begin{array}{l}\text { Volumetric rate of charring, pyrolysis, } \\
\text { and vaporization }\end{array}$ \\
\hline
\end{tabular}

which it was shown that calculating the heat release rate (HRR) by means of calorimetry for pine needles can be reinforced by the use of mass loss rate and by knowing the heat of combustion in well ventilated test conditions. Bartoli et al. [20] demonstrated that permeability drives the burning dynamics in porous beds and that the energy released increases with permeability. Additionally it was shown that for a given permeability, the fuel species have an influence on times to ignition and duration of flames. Mindykowski et al. [21] conducted experiments in the same experimental setup to investigate the piloted ignition time of litters composed of oven Mediterranean pine species and kermes oak leaves.

The porous bed can be described through CFD modeling using a multiphase formulation that allows the fire rate of spread (ROS) [22-24], and temperature field to be estimated [25]. For instance, Padhi et al. [26] described the flow field generated due to the steady burning of a shrub using the multiphase formulation. Velocity and temperature profiles were analyzed in the continuous flame region and thermal plume region and it was highlighted that the porous nature of the shrub affects air entrainment into the shrub, thus affecting the nature of the fire plume. Hence, it is important to evaluate the model's capabilities to simulate air entrainment and air mixture in the fuel bed. The use of the multiphase formulation is not new, it has been applied in numerous studies to describe the interaction between the atmospheric boundary layer with a canopy problems using isothermal flows [27-33]. However, the multiphase formulation is usually applied to simulate large-scale wildfires under complex conditions without thoroughly pre-validating or verifying if the selected submodels (i.e. the closure models) are well adapted to the fuel conditions and to the surrounding environment in which they are used, and if they allow the relevant physics to be captured [15,34-37]. For instance, degradation rates are provided from TGA analysis at a much smaller scale (microscopic) than reality [15], and drag coefficients are derived from wind tunnel tests for simple geometries at ambient temperatures [38]. In a recent study, Hoffman et al. [39] evaluated crown fire spread rate using FIRETEC [40] and WFDS [41] (both include a multiphase approach) and compared the results to a compilation of wildfire observations in North American forests [42]. It was noted that the ability to test the model was limited by a lack of environmental and fuel data such as errors associated with point-to-point comparison, which is a limitation of large scale fires. This aspect is essential because the rate of spread predictions from detailed physics-based models are sensitive to small variations in both the spatial pattern of the fuels and the environment. Therefore, this study recommended further assessment of detailed physics-based models, particularly by providing additional data regarding fuel and environmental characteristics (i.e. wind). This is why it is necessary to establish a framework tailored to the development of fire modeling with the multiphase approach. It allows to study elementary aspects of the problem and to gradually move towards complexity (by changing the fuel or environmental properties). This methodology follows a building block approach to model development and facilitates a better understanding of forest fuel flammability and of its corresponding fire dynamics.

This study includes well documented fire experiments that are conducted in a controlled environment, providing precise measurements for different fuel and ambient conditions, to quantify the influence of the parameters on the models numerical predictions. As these conditions change, some parameters and submodels in the numerical model are no longer valid and need to be adjusted. This parametric study is often overlooked at larger scale due to the excessive uncertainties caused by the large variations of fuel properties (i.e. special distribution, fuel moisture content), the unstable wind (i.e. gusts), and the strong coupling between submodels, which makes it impossible to pinpoint exactly which submodel is not behaving physically. In this study, experiments were undertaken in the FM Global Fire Propagation Apparatus (FPA) [43], similarly as in $[19,20]$ where it was demonstrated to proving repeatable conditions. Pine needle beds of varying porosity were subjected to a radiative heat and various values of airflows to observe the burning behavior under different conditions relevant to wildfire spread. Pine needle beds were used as a reference fuel because they allow repeatable fuel bed properties under laboratory settings. Mass loss rates, heat release rates, flaming times, gas emissions, and temperature fields were used to compare the experiments to the simulations. Particular attention was given to forced flow conditions extending previous work on natural convection [44] - because in wildfires, the flow is usually highly unstable and not well defined. Consequently, local variations in the flow can have important impacts on the local fire regime. However, the flow is controlled and can be well characterized in the FPA. This framework, with the appropriate modifications supports the development of large scale CFD modeling by providing inputs and indications for the necessary subscale modeling.

\section{Methods}

\subsection{Experimental details}

Experiments were conducted by burning beds of pine needles in the FPA [43] (Fig. 1). The apparatus provides a controlled environment with respect to air flow and repeatable, uniform heating conditions. Samples were exposed to a radiative heat flux of $50 \mathrm{~kW} / \mathrm{m}^{2}$ applied to the top surface of the sample, throughout the entire experiment mimicking a strong flame feedback from a larger fire surrounding the sample. This value of received heat flux 


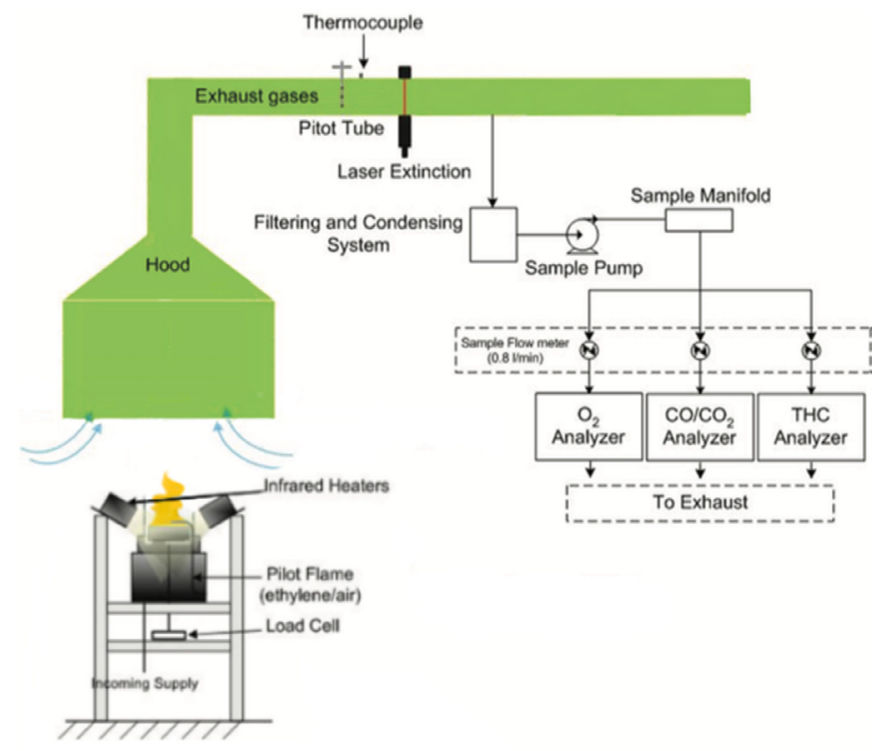

Fig.1. Overview of the Fire Propagation Apparatus (FPA).

Table 1

Summary of bulk densities and porosities.

\begin{tabular}{lll}
\hline Mass $[\mathrm{g}]$ & Bulk density $\left[\mathrm{kg} / \mathrm{m}^{3}\right]$ & Porosity $\alpha_{\mathrm{g}}[-]$ \\
\hline 8.7 & 23 & 0.96 \\
11.4 & 30 & 0.95 \\
15.0 & 40 & 0.93 \\
\hline
\end{tabular}

is representative of typical fire front propagation [45]. Dead pitch pine (Pinus rigida) needles were packed in cylindrical porous baskets (67\% opening fraction) of $12.6 \mathrm{~cm}$ diameter and $3.0 \mathrm{~cm}$ depth following the protocol used in [46]. Fuel moisture content (FMC) was determined by conditioning needles at $60{ }^{\circ} \mathrm{C}$ for $24 \mathrm{~h}$. The average FMC was $7 \%$ of the dry weight. The surface to volume ratio $\left(\sigma_{s}\right)$ is $7295 \mathrm{~m}^{-1}$, and the density $\left(\rho_{s}\right)$ is $607 \mathrm{~kg} / \mathrm{m}^{3}$.

Airflow was introduced at the inlet under the sample and passed through and around the porous sample. Three inlet fluxes of air were used No Flow (NF), Low Flow (LF) (50 L/min, corresponding to a free stream velocity of $6.67 \mathrm{~cm} / \mathrm{s})$, and High Flow (HF) $(200 \mathrm{~L} / \mathrm{min}$, corresponding to $26.8 \mathrm{~cm} / \mathrm{s})$. A hot wire anemometer (Kimo ${ }^{\circledR}$ AMI301 with a $0.01 \mathrm{~m} / \mathrm{s}$ resolution) was used to estimate the averaged velocity of the flow penetrating, and the flow circling around the porous sample. Even if the flow conditions used in this study are relatively low compared to the mean velocities that can be found in wildfires [47,48], it is important to assess the model's performance under these specific conditions, which could also be found locally during a fire. Following this framework, other flow regimes and more moderate flows could be studied.

Mass loss rate (MLR) was derived from measurements of mass using a load cell $(0.001 \mathrm{~g}$ resolution) and the exhaust gases were analyzed for composition $\left(\mathrm{CO}, \mathrm{CO}_{2}\right.$ and $\left.\mathrm{O}_{2}\right)$ using non-dispersive infrared and paramagnetic techniques at a sampling rate of $2 \mathrm{~Hz}$. Flaming time was measured with a $0.5 \mathrm{~s}$ error margin and the end of flameout time was reached when the CO concentration dropped under $4 \mathrm{ppm}$.

Three bulk densities were tested: 23,30 , and $40 \mathrm{~kg} / \mathrm{m}^{3}$, as shown in Fig. 2. The corresponding masses and porosities are listed in Table $1.40 \mathrm{~kg} / \mathrm{m}^{3}$ is the maximum density that can fit in the sample basket without over compression and breaking of the needles. $23 \mathrm{~kg} / \mathrm{m}^{3}$ corresponds to the minimal load that needs to be used to avoid significant reflection of the basket when heated [44]. These values are in the same range as typical fuel loads measured in the forest [49]. More details of the experimental setup are provided in [44]. All experimental results were averaged over 3 repetitions or more, and the error bars represent the standard deviation for all experiments.

\subsection{Computational modeling}

In this study, simulations were carried out using ForestFireFOAM (FFF) [44]. It has been previously demonstrated that FFF allows modeling the fire-induced behavior of a porous, reactive and radiative medium [44]. Conservation equations (mass, momentum, and energy) are solved for an averaged control volume at a scale sufficient to contain both coexisting gas and solid phases, and considering strong coupling between the phases [34]. Processes such as drying, pyrolysis, and char combustion are described through temperature-dependent interaction between the solid and gas phases. The gas phase combustion is represented using an extension of the Eddy Dissipation Concept (EDC), in which the characteristic time scale of fuel-air mixing is different under turbulent and laminar flow conditions [50]. This combustion model was used in a study that focused on fully-developed turbulent region of a wall flame where the diffusion time used for the laminar flow was a placeholder for the near wall region and was not verified. It is recognized that the validity of the modified EDC model for laminar flame studies still needs to be established, but this one was used in the absence of a better and simple model for laminar flames in LES. A complete description of FFF is available in [44,51] and the governing equations are presented in the Appendix. The computational domain representing the FPA in a two dimensional configuration is sketched in Fig. 3. The overall domain is a rectangle of $5 \mathrm{~m}$ wide and $2 \mathrm{~m}$ high. The mesh was composed primarily of hexahedral cells. Based on a mesh sensitivity study, a mesh resolution of $0.001 \times 0.001 \mathrm{~m}^{2}$ was determined as providing converging results in the vicinity of the sample and near the lamps. The mesh is stretched beyond the zone of interest until the boundaries reducing computational time without affecting the results. Adaptive time step is calculated based on Courant-Fredrichs-Lewy (CFL) number [52], with a maximum value of 0.7 to achieve temporal accuracy and numerical stability.

Sub-models for heat transfer, degradation, combustion, and gas emission have been implemented to allow better representation of these processes. However, in order to appropriately simulate the conditions presented above, specific submodels had to be adjusted. These submodels are presented hereafter and all other submodels that are not presented are discussed in the previous study [44].

\subsubsection{Drag forces}

In the multiphase model, the drag force acting on the solidphase is often $[22,23,36,53]$ approximated using the correlation proposed by Clift et al. [54] for estimating the drag force coefficient $\left(C_{D}\right)$ of spheres.

$C_{D}=\frac{24\left(1+0.15 R e^{0.687}\right)}{\operatorname{Re}} \times \frac{3}{8} ; 1<\operatorname{Re}<1000$

To more closely represent the cylindrical geometry of the pine needles, the drag coefficient was approximated using a pseudo fluid model for arrays of emerging circular cylinders [55]:

$$
\begin{aligned}
C_{D}= & 11 R e^{-0.75}+0.9\left[1-\exp \left(-\frac{1000}{\operatorname{Re}}\right)\right] \\
& +1.2\left[1-\exp \left(-\frac{\operatorname{Re}}{4500}\right)\right] ; \quad 0.02<\operatorname{Re}<2 \times 10^{5}
\end{aligned}
$$

The use of a correlation for arrays of cylinders is justified by the "sheltering" effect that diminishes the drag downstream an element $[56,57]$. As element spacing decreases, the bulk drag coefficient decreases [58]. Hence, correlations established for isolated 

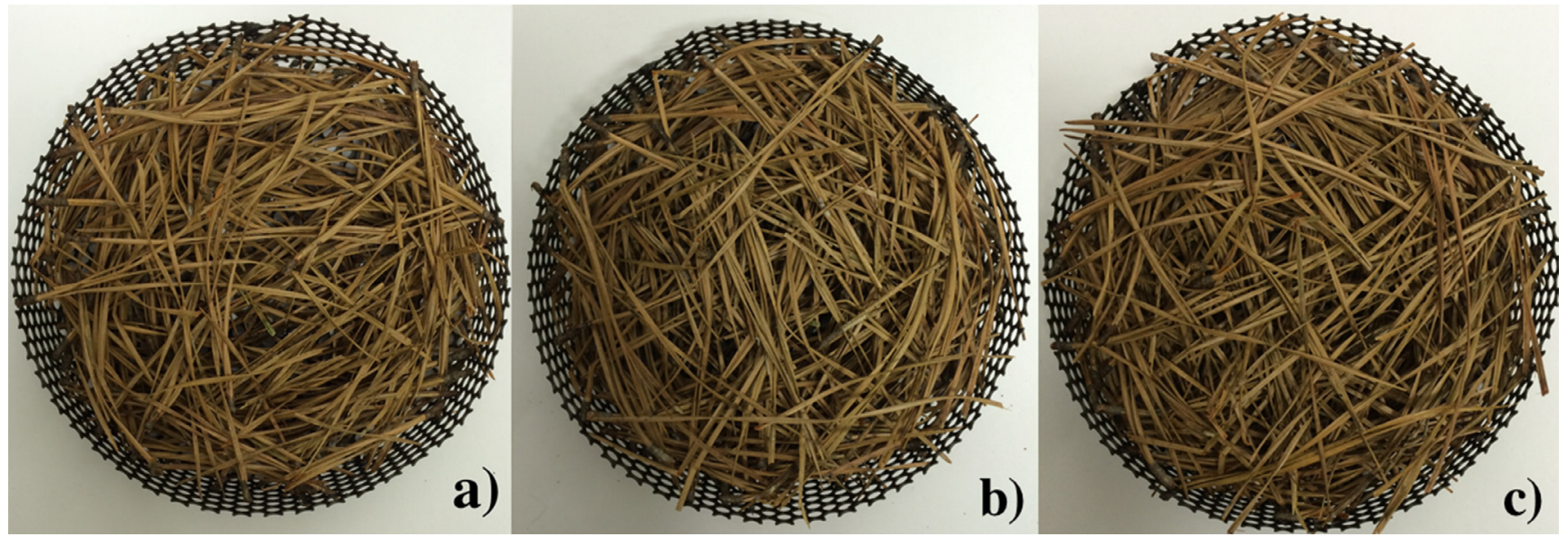

Fig. 2. Pitch pine needle samples with (a) $23 \mathrm{~kg} / \mathrm{m}^{3}$; (b) $30 \mathrm{~kg} / \mathrm{m}^{3}$; (c) $40 \mathrm{~kg} / \mathrm{m}^{3}$.

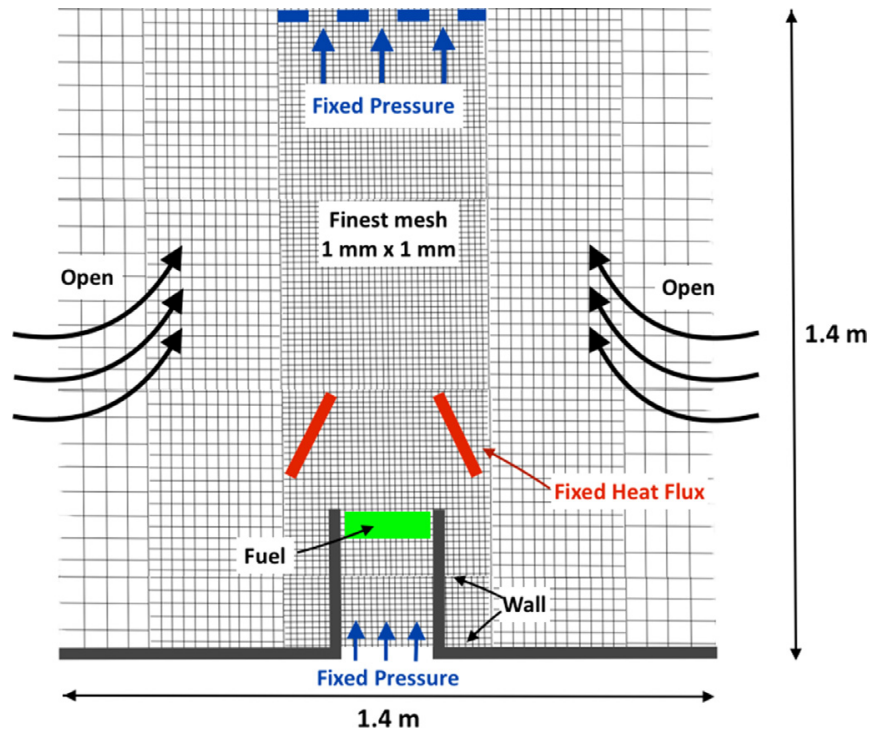

Fig. 3. Computational domain of the FPA (not to scale).

elements are no longer effective because of this strong sheltering effect.

\subsubsection{Convective heat transfer}

The term representing the contribution of convective heat transfer $Q_{C O N V}^{(S)}$ between gas and solid phases is described as follows in the gas phase energy balance equation (in Appendix):

$Q_{C O N V}^{(S)}=\alpha_{s} \sigma_{s} \chi\left(T-T_{S}\right)$

With $T$ and $T_{S}$ the gas and solid phase temperatures, respectively. The heat transfer coefficient $\chi$ is estimated from the Nusselt number [38]:

$N u=\frac{\chi D}{k}=C \operatorname{Re}^{m} \operatorname{Pr}^{n}$

where, $k$ is the air thermal conductivity $(\mathrm{W} / \mathrm{m} . \mathrm{K})$ and $D$ the equivalent diameter of a fuel particle (cylindrical needle) approximated as $4 / \sigma_{s} . D$ is also used as the characteristic length for calculating the Reynolds number. As demonstrated in [59], despite the complex vegetative structure, a simple correlation (i.e. Eq. 4) is appropriate to represent the convective term, as long as the coefficients $C, m$ and $n$ are adapted to represent the observed packing effect, or "sheltering" effect [56]. Since samples are prepared by stacking pine needles over each other, one can assume that the formulation of the convective heat transfer coefficient is similar to that of array of staggered cylinders in cross flow. Many values for $C$, $m$, and $n$ are proposed to represent the Nusselt $(\mathrm{Nu})$ number in these specific or similar conditions $[60,61]$. Values for $C, m$, and $n$ were proposed by Žukauskas [60] $(C==1.04 ; m==0.4 ; n==0.36)$, Colburn [38] $(C==0.33 ; m==0.6 ; n==1 / 3)$, Incropera and DeWitt [38] $(C==0.683 ; m==0.466 ; n==1 / 3)$, and others [61] for flow across banks of staggered tubes, for 10 or more rows of tubes and for different Reynolds regimes. All the cited correlations are widely applied in studies that are using the multiphase approach $[36,37,51,53]$, but there are no indications on which ones are more suitable.

\subsubsection{Char oxidation}

Previous work [44] has shown that using a 1st order Arrhenius submodel underestimates char oxidation rate $\left(\dot{\omega}_{\text {char }}^{\prime \prime \prime}\right)$ due to the low induced mass flux of oxygen. Consequently, the char oxidation reaction could not be sustained after flameout, despite the constant lamp radiation. In the present study, the same model was tested again, but this time in forced flow conditions to verify if it is sufficient to initiate char combustion without using more detailed modeling or additional forcing term depending on the Reynolds number to account for blowing effects [23].The char oxidation rate is estimated from the following Arrhenius equation, where $E_{C H A R}$ is the energy activation of char oxidation and $K_{C H A R}$ is the preexponential coefficient, all derived from TGA analysis [15].

$\dot{\omega}_{\text {char }}^{\prime \prime \prime}=\frac{\alpha_{s} \sigma_{s}}{v_{\mathrm{O}_{2}}} \alpha_{g} \rho Y_{\mathrm{O}_{2}} K_{C H A R} e^{\left(\frac{-E_{C H A R}}{R T_{s}}\right)}$

Char oxidation represents an important source of heat released during smoldering. Hence, it is considered that any material that forms char during its thermal decomposition can potentially sustain a smoldering process [62]. This heterogeneous oxidation is incomplete and emits a higher yield of $\mathrm{CO}$ than the gas-phase combustion [63]. By implementing the model of Evans et al. [64] into the multiphase formulation, the contribution of char combustion to the energy equation of the solid phase (in Appendix) becomes:

$\alpha_{s g} Q_{\text {char }}^{(s)}=\left[(2 \varphi-1) \Delta h_{\mathrm{CO}_{2}}+2(1-\varphi) \Delta h_{\mathrm{CO}}\right] \dot{\omega}_{\text {char }}^{\prime \prime \prime}$

with $\alpha_{s g}==0.5$, assuming that $50 \%$ of the heterogeneous combustion takes place at the surface of the solid phase and the other $50 \% \%$ takes place in the gas phase $[22,23,34,51]$.

$\varphi=\frac{2+\mathrm{CO} / \mathrm{CO}_{2}}{2 \mathrm{CO} / \mathrm{CO}_{2}+2}$ 


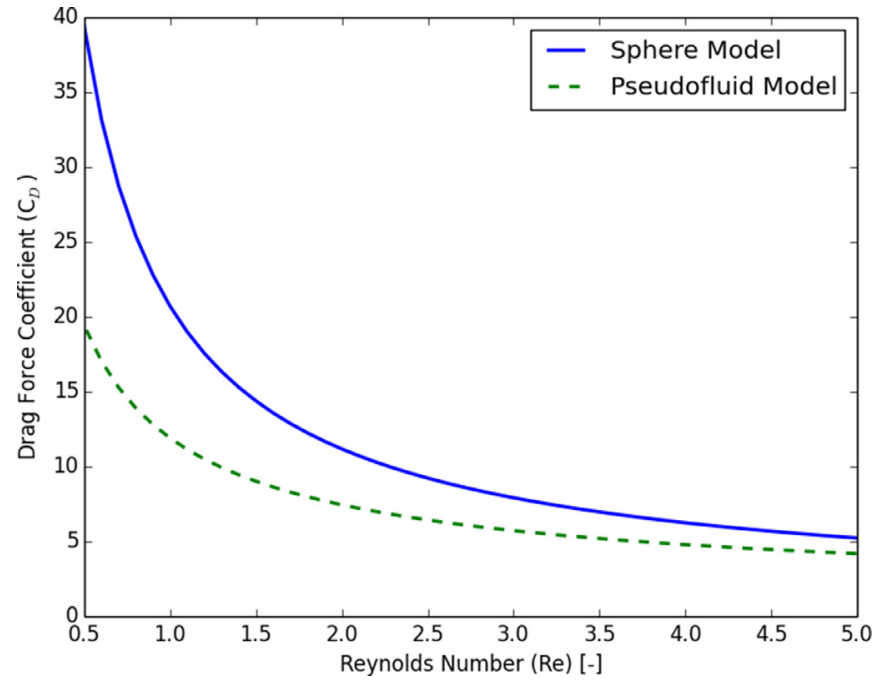

Fig. 4. Drag force coefficient estimation using different submodels.

and

$\frac{\mathrm{CO}}{\mathrm{CO}_{2}}=2500 \exp \left(-\frac{6240}{T_{S}}\right)$

The split function $(\varphi)$ allows prediction of the ratio of $\mathrm{CO}$ and $\mathrm{CO}_{2}$ concentrations produced during smoldering [65]. However, the gas phase combustion submodel (EDC) is designed to oxidize all CO mixed with oxygen, including the $\mathrm{CO}$ produced by smoldering combustion. But in reality not all $\mathrm{CO}$ is oxidized, particularly that originated from smoldering, due to the low temperature. To separate between the two types of $\mathrm{CO}$, an "inert" $\mathrm{CO}$ phase was introduced as a smoldering product.

\section{Results and discussion}

The estimation of the drag coefficient (Eq. (2)) affects the mass and the velocity of the flow that entered the sample. A misrepresentation of this value can lead to a misrepresentation of the total drag force resulting from the interaction between the solid phase and the gas phase. This results in incorrect heat transfer estimation, and poorly represented burning dynamics. Regarding the drag force coefficient estimation, the outcome of the aforementioned submodels (Eq. (1) and (2)) are presented in Fig. 4. The Reynolds $(R e)$ number was calculated using the kinematic air viscosity of dry air at $300 \mathrm{~K}\left(1.568 \times 10^{-5} \mathrm{~m}^{2} \mathrm{~s}^{-1}\right)$, resulting in $R e^{L F}==2.3$ and $R e^{H F}==9.3$. For $R e>4$, both submodels provide similar estimations, but for lower Reynolds numbers $(R e<4)$, corresponding to flows lower than $13.14 \mathrm{~cm} / \mathrm{s}$ (or $\mathrm{HF} / 2$ ), the value of $C_{D}$ is higher using Clift et al. model for a sphere [54]. However, flow velocity fields were successfully simulated using the pseudofluid model at both low flow (LF) and at high flow (HF), matching the measured velocities on top, and around the sample for tests without combustion (Fig. 5a and b). An overestimation of the drag force leads to an underestimation of the flow in the fuel bed, which affect the burning dynamics through cooling, air mixing, combustion rate, char oxidation rate, among others. When modeling large scale forest fires, these correlations are usually applied to estimate the mean drag force generated from both wind/litter and wind/tree interactions in a control volume larger than $1 \mathrm{~m} \times 1 \mathrm{~m}[40,66]$. By doing so, the flow and consequently, the fire behavior of the litter are misrepresented. Hence, vegetation elements producing different drag coefficients have to be separated.

Once ignition occurred, the observed flame was mostly laminar at the base, as shown in Fig. 6a. Transient behavior was also observed (Fig. 6b), but only in the intermittent zone of the flame, which was mostly due to the entrained air.

The difference between the three convective heat transfer coefficients outcomes presented in Fig. 7 is non negligible. For a typical HF inlet, the measured flow inside the fuel bed is approximately $0.2 \mathrm{~m} / \mathrm{s}$, corresponding to $R e^{H F}==9.3$. The correlations proposed by Zukauskas et al. and DeWitt et al. give convective coefficients $\chi>40 \mathrm{~W} / \mathrm{m}^{2} \mathrm{~K}$. However, this value is high and competes with the radiative heat transfer source term; thereby preventing the solid temperature from rising, degradation to occur, and ultimately ignition to happen. Moreover, these correlations were initially reported for moderate flow temperatures [60] and were not verified at high temperatures.

On the other hand, coefficient proposed by Colburn et al. [38] corresponded to $\chi \leq 20 \mathrm{~W} / \mathrm{m}^{2} \mathrm{~K}$, providing a more moderate heating/cooling rate. We can justify that these coefficients are more adapted to account for the sheltering effect produced when elements are close together and act as a bulk. Even though, this value is relatively low, it was demonstrated that the packing of needles generally causes the heat transfer coefficient to decrease [59].

The reason why the other correlations worked in previously cited studies is probably because the energy balance was compensated by an overestimation of the radiative heat transfer. In contrast, the radiative heat transfer of the FPA configuration was carefully examined and quantified [44].

Figure 8a illustrates the predicted temperature field of the corresponding experiment during flaming ( HF, $40 \mathrm{~kg} / \mathrm{m}^{3}$ ). Temperature ranges were in the same order of magnitude as other flames from wildland fuels $[67,68]$. The shape of the simulated flame is consistent with the experimental one (Fig. 6a). The evolution of the temperature in the solid phase is presented in Fig. $8 \mathrm{~b}$ at the top of the sample, the middle and the bottom using the correlation proposed by Colburn et al. [38]. The temperature on top, in the middle, and in the bottom increased at a slower rate than observed in NF conditions [44] before ignition due to the convective cooling. After the initial ignition, the middle temperature promptly increased. At $12 \mathrm{~s}$, the middle temperature reached $800 \mathrm{~K}$, followed by an increase in the temperature rate, corresponding to a localized ignition. As the flame propagated downwards, the bottom temperature increased until it was fully involved in the flame. Temperature measurements inside the fuel bed were not obtained in this study due to experimental limitations. Two main issues occurred with temperature measurements with forced flow. First, the vibration of the thermocouples inside the fuel bed had an influence on the pine needle arrangement in the sample, which it is important great care in having similar ones for every experimental procedure, in order to have better repeatable conditions. Second, the wiring of the thermocouples in the FPA combustion chamber obstructs the inflow. However, the simulated temperature evolution is consistent with temperature measurements conducted for Pinus strobus $\left(\sigma_{s}==10,788 \mathrm{~m}^{-1}\right)$ in the FPA under similar testing conditions (heat flux of $50 \mathrm{~kW} / \mathrm{m}^{2}$ ) [69].

Measured and simulated flaming times are plotted in Fig. 9 for different bulk densities and inlet flows. Figure 9 shows that flaming time increased with increasing bulk density. Flaming time was longer as there was more fuel to burn. It also increased with decreasing flow velocity, and the flames were maintained the longest (45 s) under natural convection at maximum bulk density. The forced flow enhanced the mixing pyrolysis gases with air and increased the burning rate. For low bulk densities, the influence of the forced flow was not as dominant as for higher bulk densities: for all flow conditions, flaming times varied between 13 and $17 \mathrm{~s}$. Since the sample was very porous (96\%), the induced air easily penetrated and provided enough oxygen to obtain well-ventilated combustion conditions. Flaming time linearly increased with bulk 

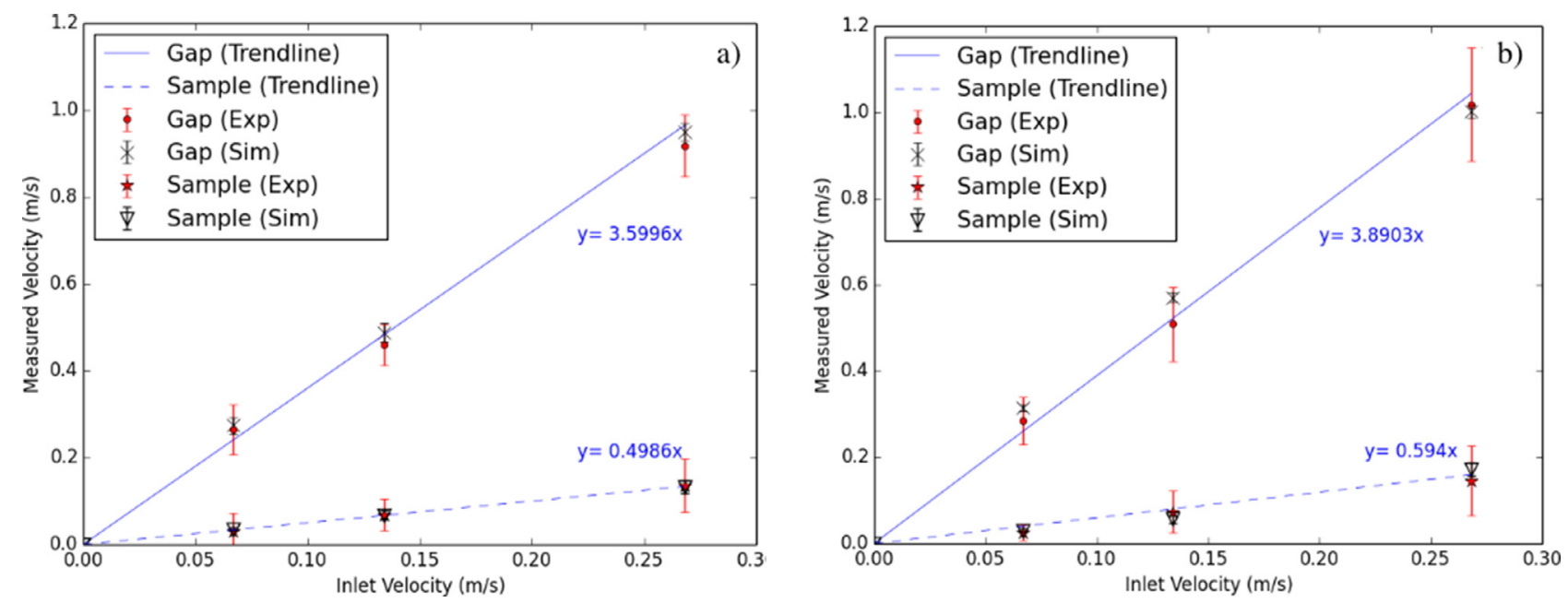

Fig. 5. Measured and simulated air velocity on the peripheral free space (gap) and on top of the fuel (sample) in the FPA at $\mathrm{HF}$ for (a) $23 \mathrm{~kg} / \mathrm{m}^{3}$ and (b) $40 \mathrm{~kg} / \mathrm{m}^{3}$.

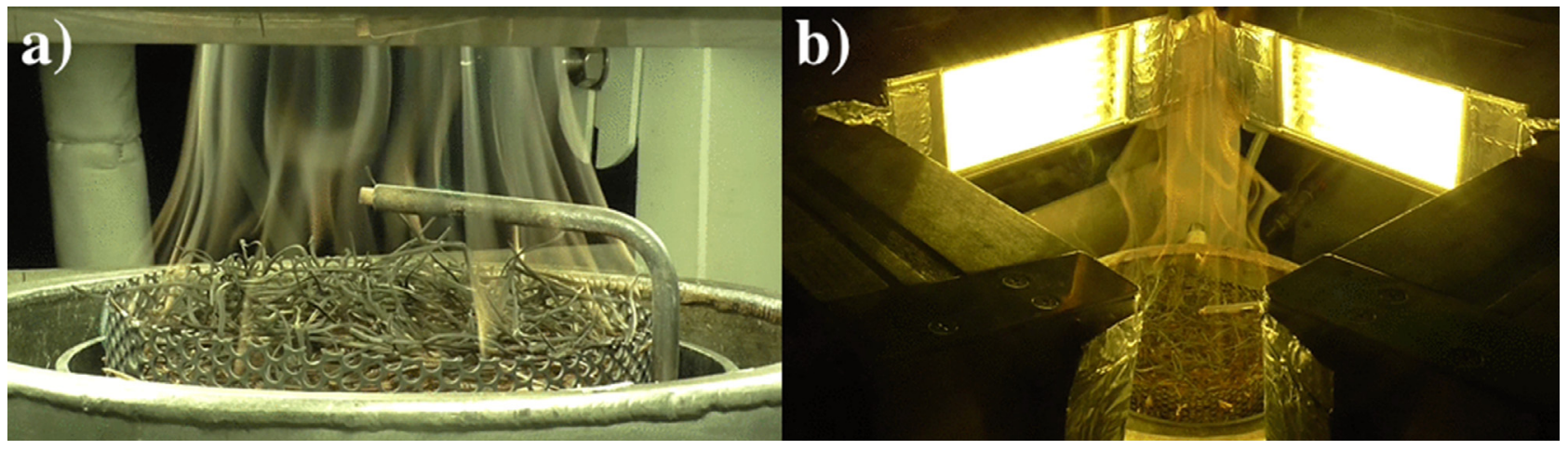

Fig. 6. Pine needles burning in the FPA (a) low view angle (b) high view angle.

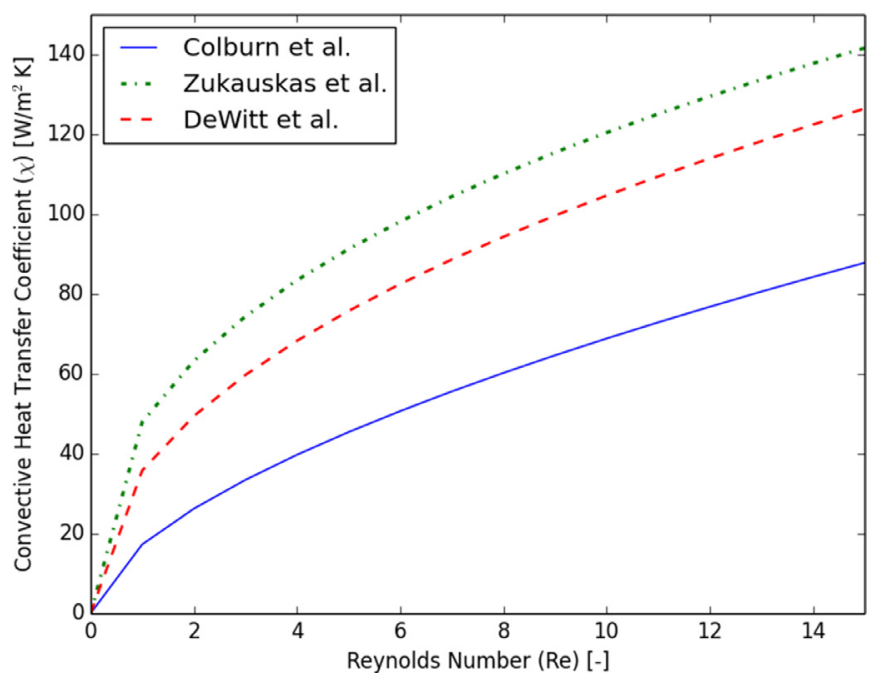

Fig. 7. Convective heat transfer coefficient estimation.

density for various flow rates since the air contribution is directly related to an increase in the combustion rate, as the latter becomes limited by the fuel available. In contrast, under natural convection the relation between flaming time and bulk density is non linear, because the combustion rate is limited by both the available fuel and the oxygen, especially for high bulk densities (92\%). For clarity, simulations are only plotted for NF and HF, which are the lower and upper bounding conditions. Also, good agreement was found for LF. Simulations slightly over predicted the flaming time by a few seconds. It is a direct consequence from using a highly efficient gas phase combustion model, where all available fuel was consumed when mixed with Oxygen. In reality the efficiency rate is not maximum (due to air dilution and cooling).

One of the main advantages of numerical simulations is the ability of separating the processes involved in the evolution of the solid phase, such as in Fig. 10, in which, the measured and simulated time evolution of the mass sample (normalized by the initial mass) were plotted for a bulk density of $40 \mathrm{~kg} / \mathrm{m}^{3}$ and HF. The simulated mass loss was split into a dry fraction, a moisture content fraction, and a char fraction. Piloted ignition was observed experimentally. However, the pilot (in Fig. 6a) was not simulated because the combustion model implies that flaming combustion occurs as soon as fuel and oxidizer are mixed. As ignition occurred faster (5s) in the simulation, all the curves were shifted to synchronize both ignition times. This is not surprising because piloted ignition is a marginal event that any small variation in the experiment or in the numerical condition can influence it. More importantly, we are interested in comparing the combustion phases following ignition. One can observe that the simulated (total) mass loss followed the mean experimental mass loss closely. The different dotted lines correspond to the three simulated fractions, giving more insight on the mass loss mechanisms. In the beginning, the mass fraction was only composed of moisture content and dry fraction. Then the moisture content evaporated during the first $13 \mathrm{~s}$ of the simulation. More dry material was lost (via pyrolysis) when ignition occurred, during which the dry fraction decreased steeply, and 

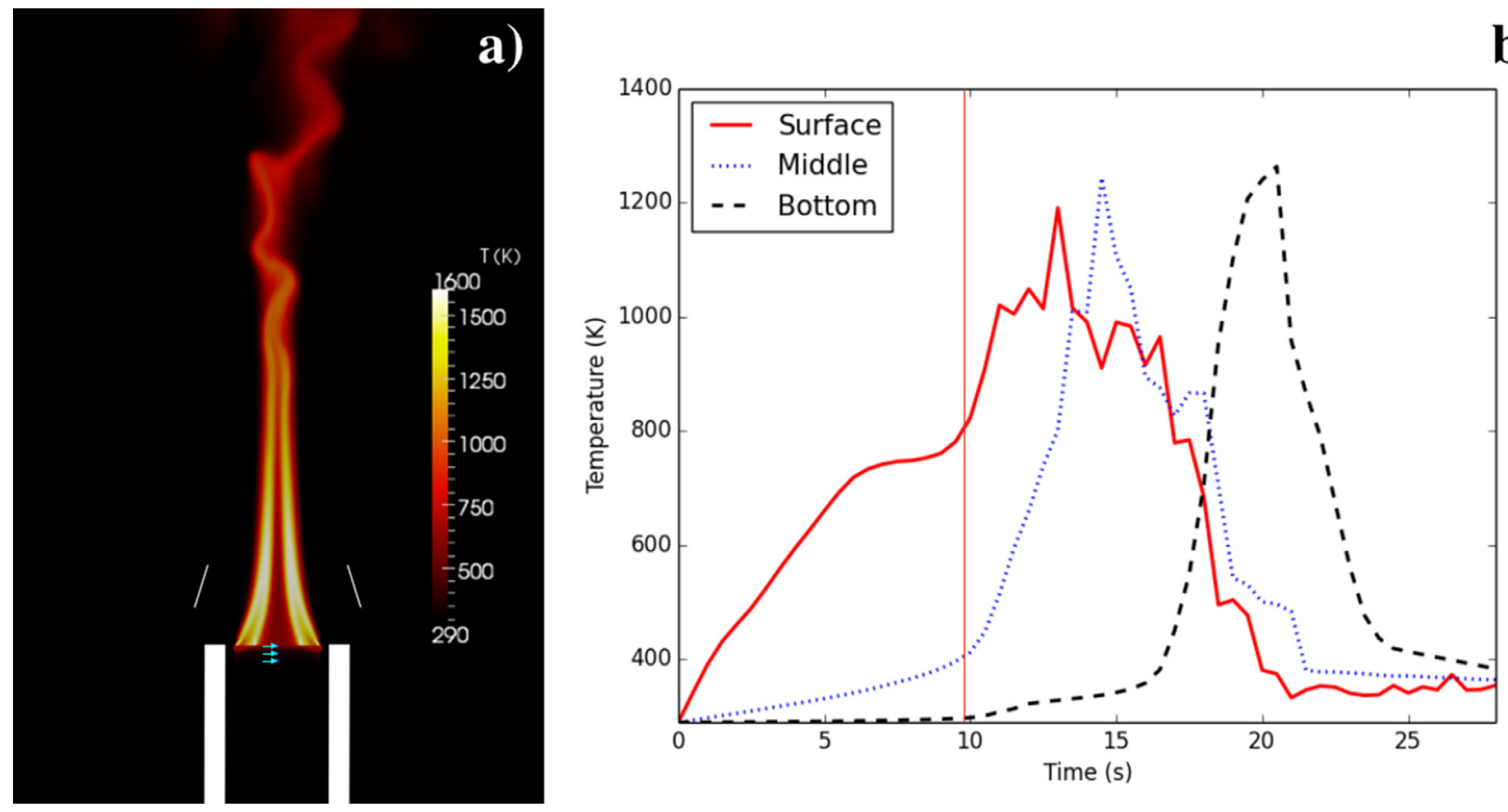

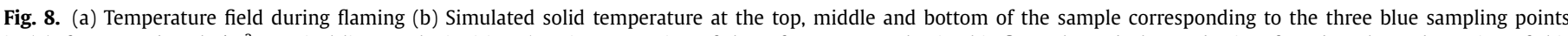

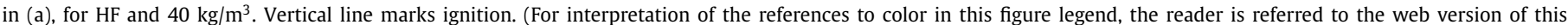
article).

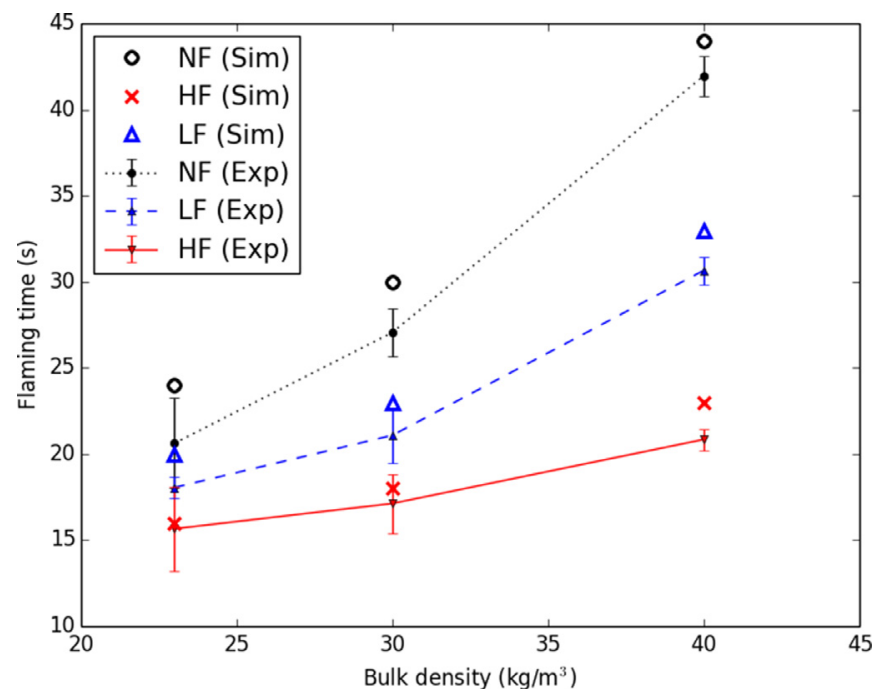

Fig. 9. Measured and simulated flaming time for different bulk densities and inlet flow. Filled markers: experiments, empty markers: simulations, error bars: standard deviations for experiments.

the char fraction formed (corresponding to flaming). The transition to smoldering combustion occurred after $30 \mathrm{~s}$ (near flameout time), during which the char oxidation reaction was dominant until the end.

Mass loss rates (MLR) were calculated from experimental and numerical mass loss data and are shown in Fig. 11 for two bulk densities: $23 \mathrm{~kg} / \mathrm{m}^{3}$ (Fig. 11a) and $40 \mathrm{~kg} / \mathrm{m}^{3}$ (Fig. 11b) at HF. A $5 \mathrm{~s}$ moving average was used to smooth experimental curves. In the first $10 \mathrm{~s}$ of both cases, the smaller slope corresponds to pyrolysis and evaporation that occurred before ignition. When ignition occurred, the slope increased steeply. The subsequent decrease corresponds to flameout (vertical line around $30 \mathrm{~s}$ ), where after mainly char oxidation occurred. The numerical results over predicted the

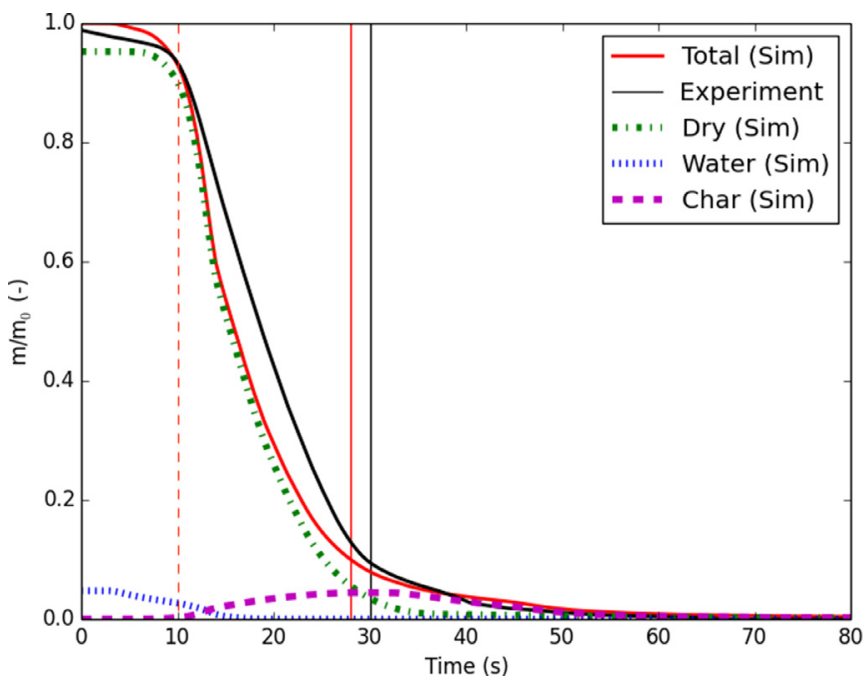

Fig. 10. Experimental and simulated mass loss, including simulated mass loss of dry, water, and char phases. Vertical dotted line corresponds to experimental and simulated ignition times. Solid vertical lines correspond to simulated and experimental flameout times respectively. ( $\mathrm{HF}-40 \mathrm{~kg} / \mathrm{m}^{3}$ ).

maximum value by around $20 \% \%$, but followed the same trend as in the experiments under both conditions.

The radiation attenuation coefficient can drastically change influence the radiation distribution in the fuel depth and affect the distribution of the mass loss rate. In these simulations, the extinction coefficient was kept as $4 / \alpha_{s} \sigma_{s}$, similarly as in a previous study [44]. However, it was demonstrated in Acem et al. [70] that the estimation of this theoretical coefficient could be could be affected by the geometrical shape by $10 \%$.

For better comparison between the different bulk densities and flow conditions, MLR were averaged for each configuration, and are presented separately during flaming and after flameout in Fig. 12a and b, respectively. During flaming (Fig. 12a), one can observe that 

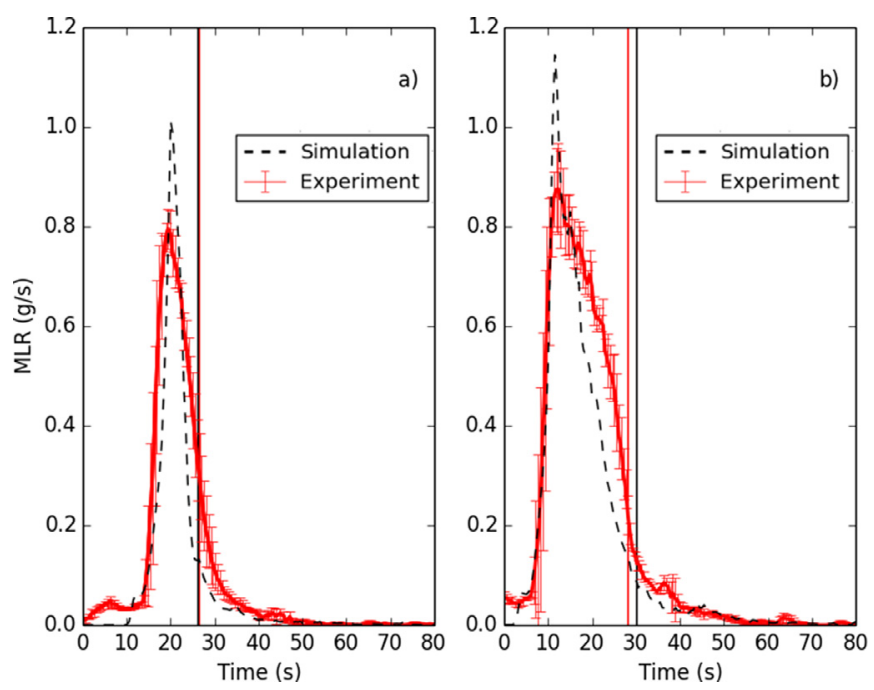

Fig. 11. Mass loss rates (MLR) at HF for different bulk densities (a) $23 \mathrm{~kg} / \mathrm{m}^{3}$ and (b) $40 \mathrm{~kg} / \mathrm{m}^{3}$. Error bars: standard deviation. Vertical line: flameout time.

the average MLR increased with an increasing inlet flow for all tested conditions because, generally the flow enhances the mixing of pyrolysis gases with air, increasing the combustion rate. The following observations can be made:

- Under HF conditions, the average value increased almost linearly with the bulk density. This is a result of the direct influence of the airflow on the combustion rate.

- For NF conditions, the average MLR increases at $30 \mathrm{~kg} / \mathrm{m}^{3}$, because there is more fuel to burn. However, it decreased at the highest bulk density, mostly due to the low ventilation conditions induced by natural convection, which slowed down the reaction.

- As for LF condition, the mean MLR remains non-monotonic as a result of the competition between radiation heating more of the solid phase with increasing bulk density (increasing $\alpha_{s}$ ), and the decreasing oxygen available to sustain the reaction.

- At the lowest bulk density $\left(23 \mathrm{~kg} / \mathrm{m}^{3}\right)$, which corresponds to the highest porosity (Table 1 ), the mean MLR is similar regardless of the flow conditions, because air can easily penetrate and provide well-ventilated combustion conditions.
- For higher bulk densities, the sample was more compact, causing more contact between pine needles, and more shadowing effect. Therefore, there was less contact with the gas phase. As the extinction length $\left(\sim 4 / \alpha_{s} \sigma_{s}\right)$ [71] changes from $13.7 \mathrm{~mm}$ to $7.8 \mathrm{~mm}$, between 23 and $40 \mathrm{~kg} / \mathrm{m}^{3}$, respectively, radiation cannot penetrate deeper in the sample body. The optical thickness defined as the ratio between the depth of the sample $(3 \mathrm{~cm})$ and the extinction length shows that the sample is optically thick (2.19 and 3.84 for 23 and $40 \mathrm{~kg} / \mathrm{m}^{3}$, respectively).

- When the total amount of radiation is distributed on a shallow layer the limited factor is the amount of fuel available for pyrolysis, However, when the same amount of energy is distributed deeper in the fuel (i.e. low bulk density), more mass undergoes pyrolysis. Ultimately, pyrolysis of a denser fuel will be limited by the heat transferred downwards, which is correlated to the bulk density.

- Between experiments and simulations with and without flow, we can highlight the existence of two regimes. The oxygen limited oxygen regime (no wind) and the fuel limited regime (with wind) [72]. Because the mean MLR is not a monotonic function of the density in NF and LF conditions, we can determine that the combustion is limited by oxygen supply (via saturation).

Overall, simulations are consistent with measurements, regardless of the peak values that are slightly overestimated numerically, as shown in Fig. 11a and b, and in [44].

Concerning the average MLR after flameout presented in Fig $12 \mathrm{~b}$, we can safely assume that mass loss is driven by smoldering. Since the latter occurs at very slow reaction rate, the average MLR is one order of magnitude smaller than the one of flaming, which makes it difficult to distinguish tendencies. Globally, one can observe that the average MLR increases with bulk density and with the flow, because there is more fuel and more air, respectively. This is consistent with Eq. (5), where the char oxidation rate is proportional to the oxygen concentration and to the bulk density. The numerical predictions in HF compared well with measurements, as a result of the proper flow and heat transfer estimation. However, results under NF conditions did not match the experimental results because the char oxidation was not sustained due to the low air supply in natural convection, as explained in [44]. Hence, the reaction only occurred in the few seconds after flameout then dropped, resulting in a high average MLR compared to the experiments, which lasted longer. The smoldering time in NF could be
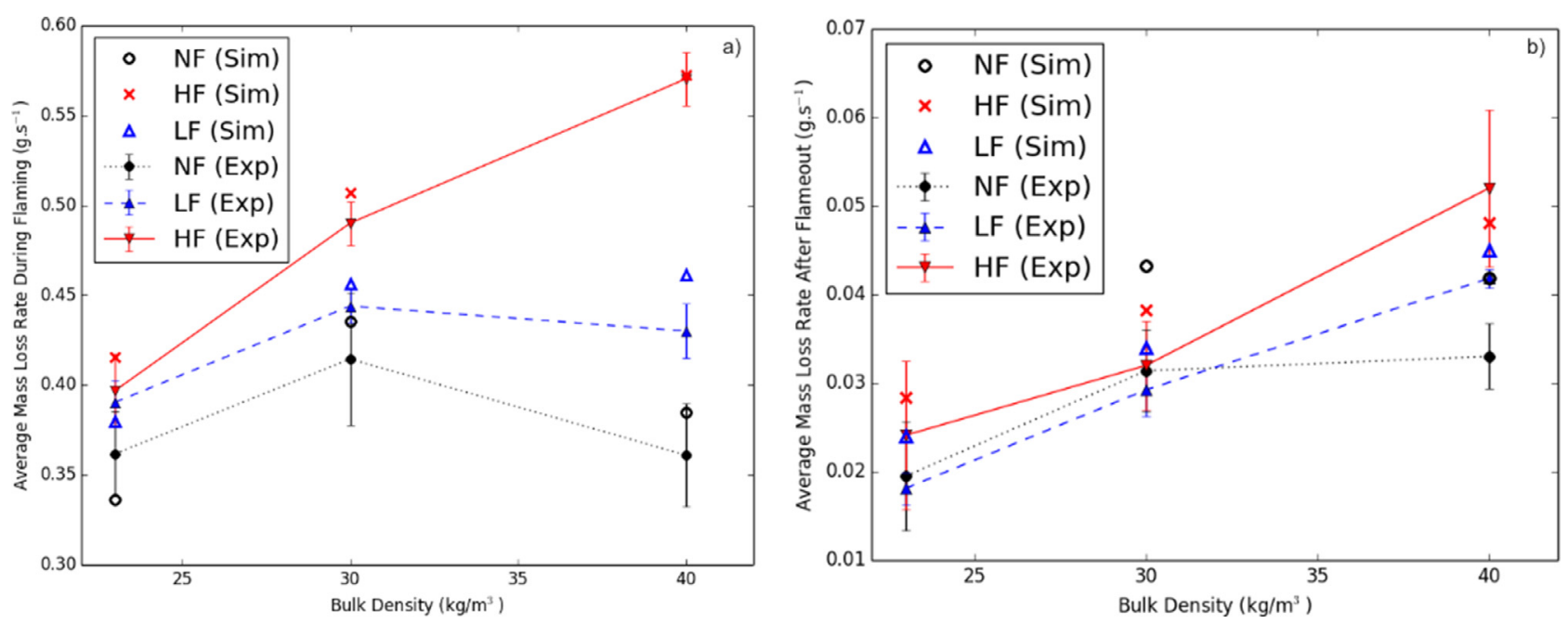

Fig. 12. Averaged values for measured and simulated mass loss rates (a) during flaming (b) after flameout. 

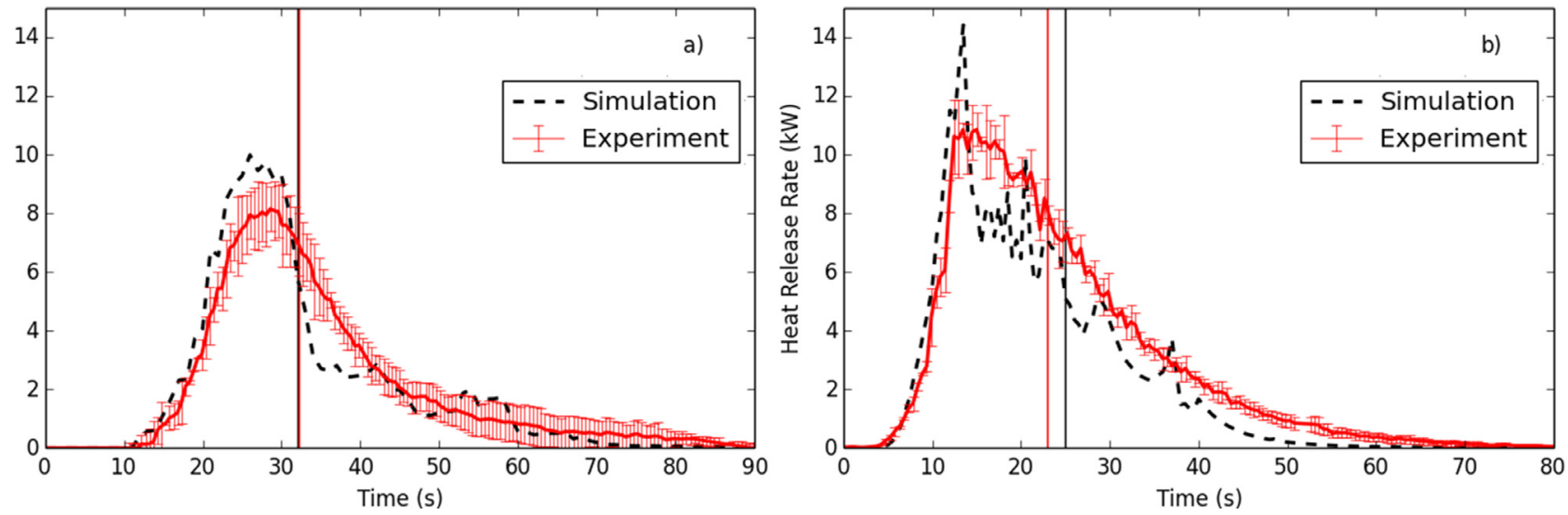

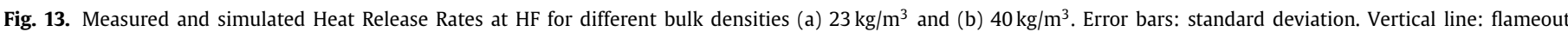
time.
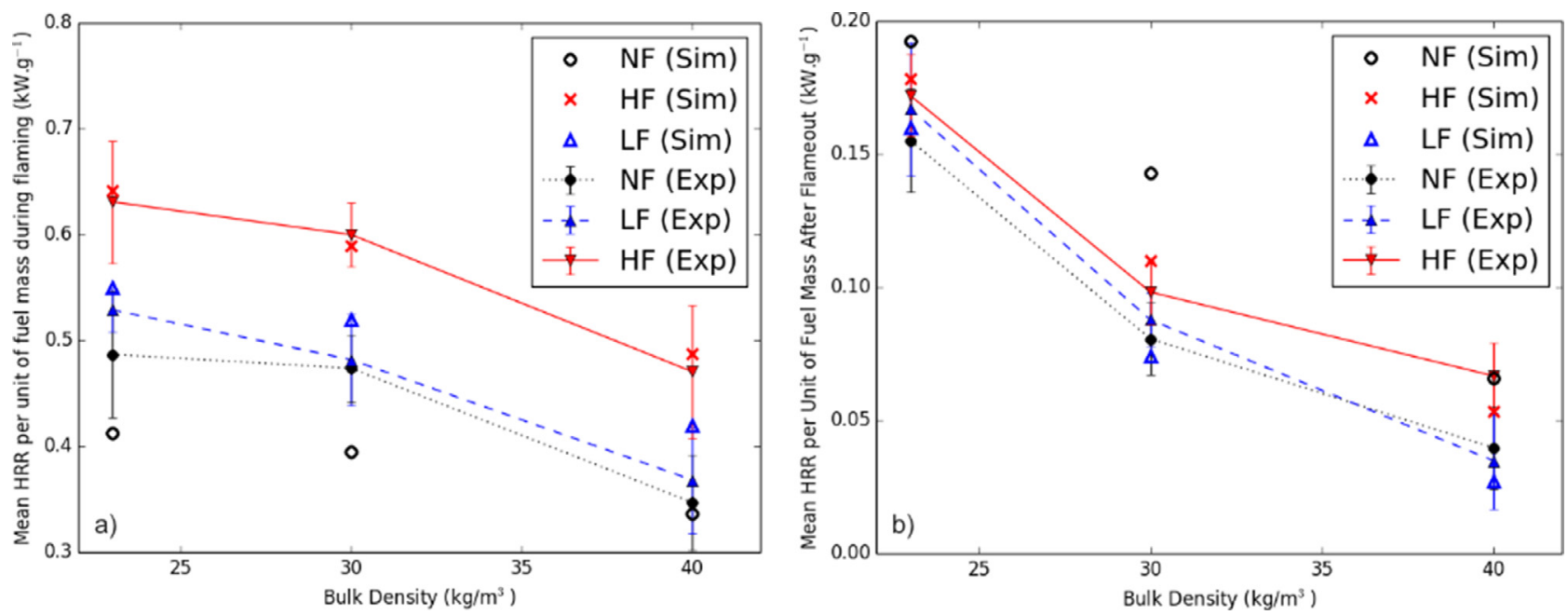

Fig. 14. Averaged values for measured and simulated heat release rates (HRR) per unit of initial fuel mass (a) during flaming (b) after flameout.

enhanced by either testing a more comprehensive model for estimating the char combustion rate, or by accounting for the increase of the surface to volume ratio in the solid phase (which is constant) as a result of the char pores that are formed in the fuel.

The measured and simulated Heat Release Rate (HRR) are presented in Fig. 13 for two bulk densities at HF. Computed curves were time-shifted so that they coincide with experimental curves when ignition occurred. The peak HRR was slightly over estimated for both cases, a result of the high MLR peaks. Nevertheless, the overall trend is matched and the total heat released is similar. The peak HRR at $40 \mathrm{~kg} / \mathrm{m}^{3}$ (Fig. 13b) is at approximately $11 \mathrm{~kW}$, which is comparable to results in $[20,69]$ for Aleppo pine (Pinus halepensis) tested under similar conditions. The transition between flaming and smoldering (at flameout) was better predicted numerically for the higher bulk density (Fig. 13b). However, for the lower bulk density (Fig. 13a), an abrupt transition can be noticed only in the simulation. This behavior can be justified by the larger amount of fuel burning (i.e. higher solid fraction) available to increase the heat transfer from solid to solid, and to better sustaining char oxidation after flameout.

For better illustration of the influence of the porosity in the HRR, averaged values for measured and simulated HRR were normalized over their corresponding initial fuel mass $\left(\overline{H R R} / m_{0}\right)$ and are presented during flaming and after flameout, in Fig. 14a and $b$, respectively. The normalization allows better comparison of the energy rate released between different bulk densities. In Fig 14a,
$\overline{H R R} / m_{0}$ globally increases with the flow. This is consisted with the observed MLR (Fig. 12a) and with the shorter flaming times for higher flow conditions. Essentially, Higher HRR is reached for shorter flaming time due to the better mixing, and consequently the enhanced the combustion rate. The observed $\overline{\mathrm{HRR}} / m_{0}$ trends to decrease with an increasing bulk density, which is also consistent with the aforementioned observations about the competition between radiation penetration and oxygen availability. As for the numerical predictions, these tendencies are well matched at high flow but cannot be obtained under NF conditions due to the low combustion rate estimated [44].

Regarding $\overline{H R R} / m_{0}$ after flameout (Fig. 14b), overall the measured values are also an order of magnitude lower than during flaming. They decrease with an increasing bulk density, since more air can reach the reacting solid phase for lower bulk densities. $\overline{H R R} / m_{0}$ is consistently slightly higher at $\mathrm{HF}$, especially for the higher bulk density. Simulations of HF conditions matched the measurements. However, for NF condition, a high average MLR was calculated after flameout (Fig. 12b). Consequently, the calculated $\overline{H R R} / m_{0}$ was overestimated compared to measurements only because a higher HRR was released over a shorter period of time. However, the total energy released is smaller, since not all the char was oxidized in NF.

Figure 15a, b, and c describe the evolution of the fuel and oxygen mass fractions inside the fuel bed under HF conditions at ignition, $5 \mathrm{~s}$ and $15 \mathrm{~s}$ after ignition, respectively. It can be noted that 

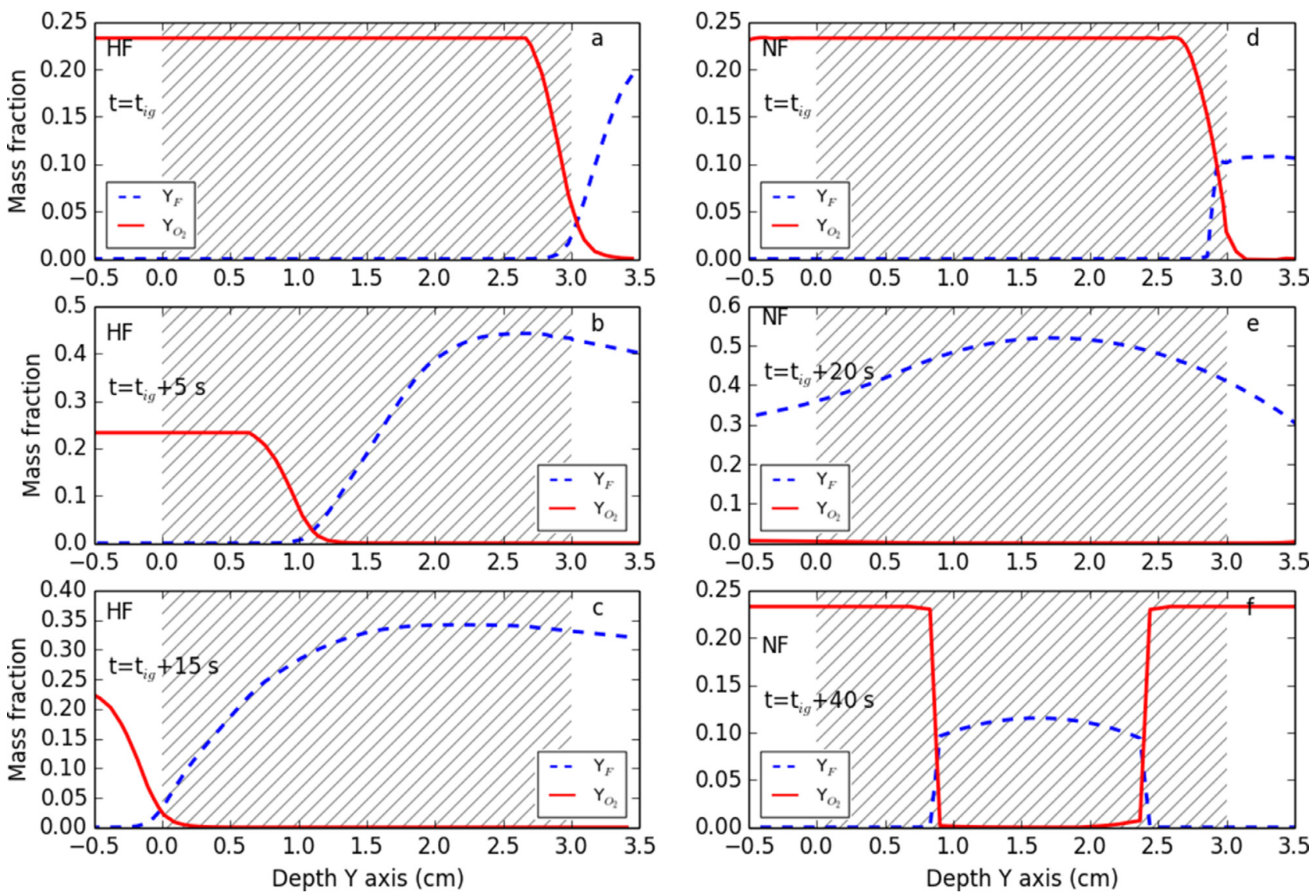

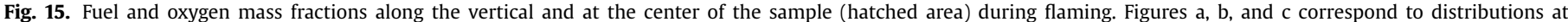
ignition, $5 \mathrm{~s}$ and $15 \mathrm{~s}$, respectively for HF conditions. Figures d, e, and f correspond to distributions at ignition, $20 \mathrm{~s}$ and $40 \mathrm{~s}$, respectively for NF conditions.

the propagation occurs from top to bottom, which is in agreement with the experimental observations. Moreover, the evolution of the mass fractions (step) are representative of a typical diffusion flame, meaning that no partial mixing in involved. It is clear that the oxygen is completely consumed in the first cell of the reaction zone.

On the other hand, Fig. 15d, e, and f represent the evolution of the mass fraction in NF conditions. In Fig. 15d, the conditions at ignition are similar to those of encountered with HF (Fig. 15a). As the flame propagates slower in NF, Fig. 15e and f show the mass fractions 20 and $40 \mathrm{~s}$ after ignition. It appears that the entire fuel sample is embedded in the fuel rich zone and that there is no sufficient oxygen inside it to ensure flaming combustion. Anecdotal observations of experiments using pine needles in the cone calorimeter under natural convection allowed to see the flame burning below the sample, which is characteristic of the behavior of a fuel rich diffusion flame and confirms the prediction from Fig. 15e and $\mathrm{f}$. This behavior was also observed in the FPA in natural convection but it was harder to see because of the light of the heaters.

Figures 16 and 17 present the experimental and simulated time evolution of $\mathrm{CO}$ and $\mathrm{CO}_{2}$ generation for a fuel bulk density of $40 \mathrm{~kg} / \mathrm{m}^{3}$ in HF and NF, respectively. The experimental values were measured in the exhaust duct, similarly the simulated values were obtained at the outlet boundary. Useful information can be extracted from these figures and three phases can be defined. During the first phase, which occurs just after ignition, only flaming is involved as $\mathrm{CO}_{2}$ production increases. During the second phase, flaming and smoldering occur simultaneously. Finally, during the third phase which is after flameout, only heterogeneous combustion occurs. By comparing Figs 16 and 17, it can be noted that the time of each phase can be very different. In natural convection (Fig 17),

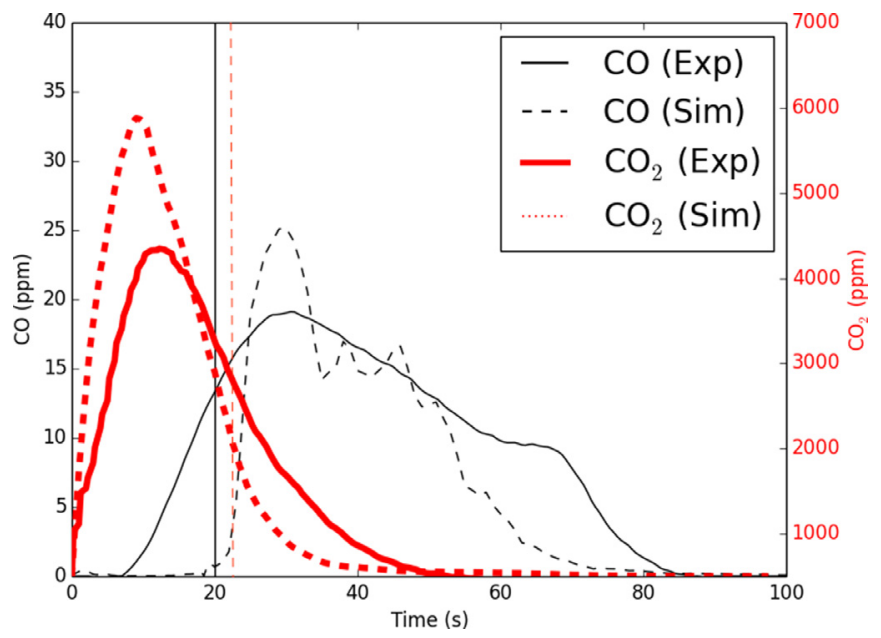

Fig. 16. Measured and simulated $\mathrm{CO}$ and $\mathrm{CO}_{2}$ production $\left(\mathrm{HF}-40 \mathrm{~kg} / \mathrm{m}^{3}\right.$ ). The vertical lines represent the experimental (red dashed) and the numerical (black solid) flameout times. Plots are shifted to have ignition at $0 \mathrm{~s}$. (For interpretation of the references to color in this figure legend, the reader is referred to the web version of this article).

the transition from flaming to smoldering (second phase) occurs in a shorter time than in forced flow (Fig 16). This behavior is mainly due to the additional oxygen supplied inside the fuel bed by the forced flow, which allows flaming and smoldering to occur simultaneously. In contrast, smoldering occurs mainly after flameout in natural convection. The differences in $\mathrm{CO}$ curves between $\mathrm{HF}$ and 


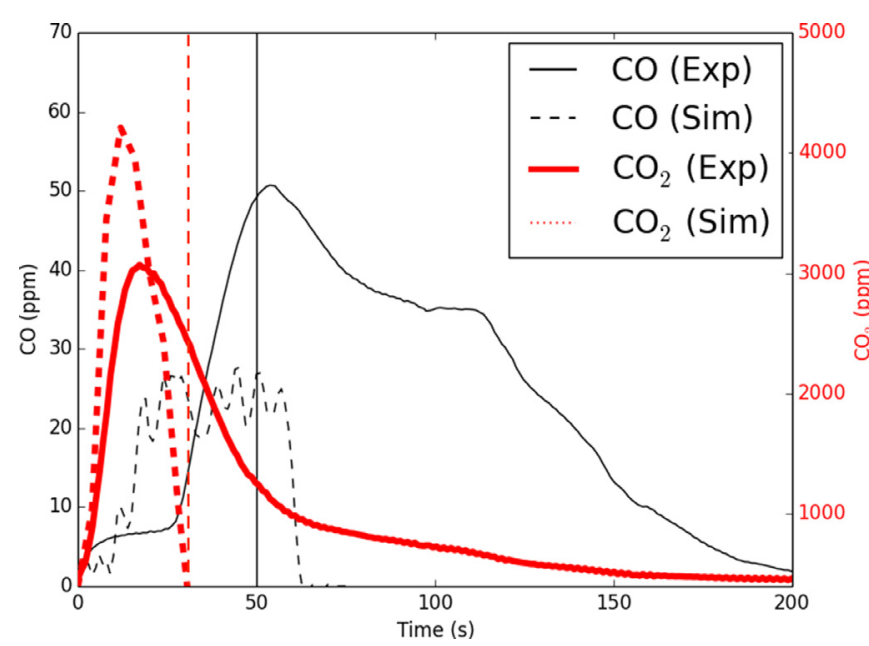

Fig. 17. Measured and simulated $\mathrm{CO}$ and $\mathrm{CO}_{2}$ production $\left(\mathrm{NF}-40 \mathrm{~kg} / \mathrm{m}^{3}\right.$ ). The vertical lines represent the experimental (red dashed) and the numerical (black solid) flameout times. Plots are shifted to have ignition at $0 \mathrm{~s}$. (For interpretation of the references to color in this figure legend, the reader is referred to the web version of this article).

NF (Figs 16 and 17) demonstrate the changing in behavior in the combustion process. CO concentration is an indicator of the two stages of combustion when correlated to visual observations. The first step increase in Fig. 17 is due to the ignition of the sample. A steady production of CO follows, which corresponds to the flaming stage (first phase) with possibly an oxidation of $\mathrm{CO}$ in the flame. The consequent increase is due to the decrease of the flame and the initiation of smoldering combustion. The two processes overlap during this stage (second phase). After flameout, CO production peaks due to the sole occurrence of smoldering combustion (third phase). In contrast, the steady state of the CO disappears in HF. A faster combustion time was observed with embers starting to glow before flameout. These tendencies confirm the measurements and the observations described by Schemel et al. [19].

Concerning the numerical predictions, all the main tendencies were captured qualitatively by the model, even though the quantitative predictions were not accurate. In both configurations, the simulations overestimated the $\mathrm{CO}_{2}$ production during flaming because the entire pyrolysis products were consumed in the gas phase due to the nature of the combustion model. In Fig. 16, smoldering was not activated during flaming, therefore, no CO was detected in the simulation. In reality, not all CO from pyrolysis is entirely oxidized, due to dilution with air and cooling. Indeed, the concentration of measured $\mathrm{CO}$ increased as the flame was quenching and more smoldering was occurring. An extinction model could be added to account for the unburned gases and better represent the incomplete combustion in the flame, especially at a larger scale [73]. However, its absence did not severely influence the burning dynamics of the pine needle bed (which was the focus of this work), as it was mainly driven by the incident radiation coming from the lamps. In Fig. 17, numerical CO is detected even before flame out time, which is due to an early activation of the smoldering process, as it was observed experimentally. Hence, both burning dynamics in NF and HF are captured by the model. The experimental peak value for $\mathrm{CO}$ was $25 \mathrm{ppm}$ for $\mathrm{HF}$, whereas it was $35 \mathrm{ppm}$ for the simulation. This is also due to the combustion model that overestimated the combustion efficiency in the gas phase and had little influence on the burning dynamics. An adjustment will certainly be needed for large fires, where extinction is likely play a role, especially if the model is to be used to estimate fire emissions.

\section{Conclusion}

The goal of the presented framework was to assess the relevance and the performance of the submodels used to close CFD models particularly with the multiphase approach for wildfires. Some submodels were successfully adapted in a specific and realistic range of conditions, which allowed improving burning rate estimations and better describing the underlying physics. Moreover, the importance and the implications of using appropriate submodels were also demonstrated. By comparing simulations to experiments with various fuel bulk densities and various inlet flows, at a constant applied heat flux with a well defined fuel, it was shown which submodels need to be appropriately defined in order to provide acceptable predictions. Because of the strong coupling between the different submodels, the proposed framework of using controlled experiments and matching simulations at a small scale is necessary for choosing the adequate submodels. This will ensure that the physics involved in the burning of the fuel are correctly captured before predicting fire spread at a larger scale. The main results are summarized as follows:

- The estimation of the drag force coefficient affects the flow field inside the porous fuel, consequently it affects the associated burning dynamics during flaming and smoldering. The proposed correlations can be used for subgrid modeling and included in large scale simulations to represent the drag force through litter beds separately from the one for trees.

- For the convective heat transfer coefficient, we have verified that Colburn coefficients are appropriate for these experimental conditions, whereas other cited coefficients can prevent the fuel from igniting.

- Under forced flow conditions, the char oxidation model based on a single step Arrhenius equation is sufficient for characterizing smoldering combustion, and especially mass loss after flameout. However, this model is not adapted under natural convection, and further investigation is necessary.

- The additional split function in the char oxidation allows predicting an acceptable gas emission and adequately modeling the transition between flaming and smoldering emission.

- Overall, the selected gas phase combustion model allowed a successful prediction of the burning dynamics of the solid phase in the chosen range of conditions. However, it needs further improvements for supporting emission estimations.

\section{Acknowledgments}

The authors gratefully acknowledge the Fire Dynamics Group at FM Global for the help provided in the development of ForestFireFOAM. Insights offered by G. Accary are most appreciated. This work was granted access to the HPC resources of Aix-Marseille Université financed by the project Equip@Meso (ANR-10-EQPX-2901) of the program "Investissements d'Avenir " supervised by the French Agence Nationale pour la Recherche.

\section{Appendix. Governing equations in FFF}

The gas phase is governed by a set of transport equations representing the mass balance equations:

$$
\frac{\partial \alpha_{g} \bar{\rho}}{\partial t}+\frac{\partial \alpha_{g} \bar{\rho} \tilde{u}_{j}}{\partial x_{j}}=\left(1-v_{a s h}\right) \dot{\omega}_{c h a r}^{\prime \prime \prime}+\dot{\omega}_{\text {vap }}^{\prime \prime \prime}+\left(1-v_{c h a r}\right) \dot{\omega}_{p y r}^{\prime \prime \prime}
$$

where $\sim$ is the Favre filter operator, $v_{\text {char }}$ and $v_{a s h}$ are the char and ash fractions, respectively. For forest fuel $v_{\text {char }} \sim 0.3$ and $v_{\text {ash }}$ 
$\sim 0.05[15,74]$. The momentum equation is defined as:

$$
\begin{aligned}
\frac{\partial \bar{\rho} \tilde{u}_{i}}{\partial t} & +\frac{\partial\left(\alpha_{g} \bar{\rho} \tilde{u}_{i} \tilde{u}_{j}\right)}{\partial x_{j}}=-\frac{\partial \bar{p}}{\partial x_{i}}+\frac{\partial}{\partial x_{j}} \\
& \times\left(\alpha_{g} \bar{\rho}\left(v+v_{t}\right)\left(\frac{\partial \tilde{u}_{i}}{\partial x_{j}}+\frac{\partial \tilde{u}_{j}}{\partial x_{i}}-\frac{2}{3} \frac{\partial \tilde{u}_{k}}{\partial x_{k}} \delta_{i j}\right)\right)+\alpha_{g} \bar{\rho} g_{i}-F_{D}
\end{aligned}
$$

$v$ is the molecular viscosity, $v_{t}$ is the sub grid scale viscosity, and $p$ is the pressure. $F_{D}$ represents the drag force source term resulting from the interaction between the gas flow and the solid phase, and is defined as:

$F_{D}=\alpha_{g} \rho C_{D} \frac{\alpha_{s} \sigma_{s}}{2}|u| u_{i}$

Since thermal equilibrium is not assumed between the solid fuel particle and gaseous phase, the temperature in the solid phase is solved separately, in the following equation:

$C_{p}^{(S)} \alpha_{s} \rho_{s} \frac{d T_{S}}{d t}=Q_{ \pm}^{(S)}-\Delta h_{v a p} \dot{\omega}_{v a p}^{\prime \prime \prime}-\Delta h_{p y r} \dot{\omega}_{p y r}^{\prime \prime \prime}-\alpha_{s g} Q_{c h a r}^{(S)}$

with $Q_{ \pm}^{(S)}$ the energy balance on the solid phase exchanged with the gaseous phase by convection and radiation. $C_{p}{ }^{(S)}$ is the specific heat capacity of the solid phase, $\Delta h_{c h a r}, \Delta h_{p y r}, \Delta h_{\text {vap }}$ are the heat of reaction for charring, pyrolysis, and evaporation, respectively. The time evolution of the fuel is characterized by the variation of its dry, water, and char mass fractions. They can be described by the following three ordinary differential equations:

$\frac{d \alpha_{\mathrm{s}} \rho_{\mathrm{s}} \varphi_{\mathrm{H}_{2} \mathrm{O}}^{(S)}}{d t}=-\dot{\omega}_{v a p}^{\prime \prime \prime}$

$\frac{d \alpha_{s} \rho_{s} \varphi_{D R Y}^{(S)}}{d t}=-\dot{\omega}_{p y r}^{\prime \prime \prime}$

$\frac{d \alpha_{s} \rho_{s} \varphi_{\text {char }}^{(S)}}{d t}=\left(v_{\text {char }}-v_{\text {soot }}\right) \dot{\omega}_{\text {pyr }}^{\prime \prime \prime}-\left(\frac{v_{\text {ash }}}{v_{\text {char }}}+1\right) \dot{\omega}_{\text {char }}^{\prime \prime \prime}$

The global mass balance equation for the solid phase is:

$\frac{d\left(\alpha_{s} \rho_{s}\right)}{d t}=\left(v_{\text {char }}-v_{s o o t}-1\right) \dot{\omega}_{p y r}^{\prime \prime \prime}-\dot{\omega}_{c h a r}^{\prime \prime \prime}-\dot{\omega}_{\text {vap }}^{\prime \prime \prime}$

Assuming that the solid consumption is only due to char combustion. The balance equation for the solid fraction is resolved following:

$\frac{d \alpha_{s}}{d t}=-\frac{\dot{\omega}_{c h a r}^{\prime \prime \prime}}{\rho_{s}}$

Finally, the energy balance of the gas phase is written as:

$$
\begin{gathered}
\frac{\partial\left(\alpha_{g} \bar{\rho} \tilde{h}\right)}{\partial t}+\frac{\partial\left(\alpha_{g} \bar{\rho} \tilde{u}_{j} \tilde{h}\right)}{\partial x_{j}}=\frac{D \bar{p}}{D t}+\frac{\partial}{\partial x_{j}}\left(\alpha_{g} \bar{\rho}\left(\alpha_{D}+\frac{v_{t}}{P r_{t}}\right) \frac{\partial \tilde{h}}{\partial x_{j}}\right) \\
-Q_{\text {CONV }}^{(S)}+Q_{R A D}+Q_{C O M B}-\left(1-\alpha_{s g}\right) Q_{\text {char }}^{(s)}
\end{gathered}
$$

where $h$ is the enthalpy, $\alpha_{D}$ is the thermal diffusivity (considering a unity Lewis number approximation). $Q_{C O M B}$ and $Q_{R A D}$ are the source term for combustion and radiation in the gas phase, respectively, as described in [44].

\section{References}

[1] A.C. Fernandez-Pello, The solid phase, in: G. Cox (Ed.), Combustion Fundamentals of Fire, Academic Press, 1994, pp. 31-100.

[2] V. Babrauskas, Ignition Handbook, Fire Science Publishers - Society of Fire Protection Engineers, Issaquah, WA, 2003.

[3] D. Drysdale, An Introduction to Fire Dynamics, 3rd ed, John Wiley \& Sons, Ltd, Chichester, UK, 2011.

[4] A. Tewarson, R.F. Pion, Flammability of plastics-I. Burning intensity, Combust. Flame 26 (1976) 85-103, doi:10.1016/0010-2180(76)90059-6.

[5] T.J. Ohlemiller, Modeling of smoldering combustion propagation, Prog. Energy Combust. Sci. 11 (1985) 277-310, doi:10.1016/0360-1285(85)90004-8.
[6] Y. Sohn, S.W. Baek, T. Kashiwagi, Transient modeling of thermal degradation in non-charring solids, Combust. Sci. Technol. 145 (1999) 83-108.

[7] A. Tewarson, Combustion efficiency and its radiative component, Fire Saf. J. 39 (2004) 131-141, doi:10.1016/j.firesaf.2003.07.004.

[8] S.I. Stoliarov, S. Crowley, R.E. Lyon, G.T. Linteris, Prediction of the burning rates of non-charring polymers, Combust. Flame 156 (2009) 1068-1083, doi:10.1016/ j.combustflame.2008.11.010.

[9] K. Nakabe, K.B. McGrattan, T. Kashiwagi, H.R. Baum, H. Yamashita, G. Kushida, Ignition and transition to flame spread over a thermally thin cellulosic sheet in a microgravity environment, Combust. Flame 4 (1994) 361-374, doi:10.1016/ 0010-2180(94)90175-9.

[10] S. Olson, T. Kashiwagi, O. Fujita, M. Kikuchi, K. Ito, Experimental observations of spot radiative ignition and subsequent three-dimensional flame spread over thin cellulose fuels, Combust. Flame 125 (2001) 852-864, doi:10.1016/ S0010-2180(00)00249-2.

[11] W. Parker, Prediction of the heat release rate of wood, Fire Saf. Sci. 1 (1986) 207-216, doi:10.3801/IAFSS.FSS.1-207.

[12] N. Boonmee, J.G. Quintiere, Glowing ignition of wood: the onset of surface combustion, Proc. Combust. Inst. 30 (2005) 2303-2310, doi:10.1016/j.proci. 2004.07.022.

[13] C. Di Blasi, Modeling chemical and physical processes of wood and biomass pyrolysis, Prog. Energy Combust. Sci. 34 (2008) 47-90, doi:10.1016/j.pecs.2006. 12.001.

[14] T. Fateh, T. Rogaume, F. Richard, Multi-scale modeling of the thermal decomposition of fire retardant plywood, Fire Saf. J. 64 (2014) 36-47, doi:10.1016/j. firesaf.2014.01.007.

[15] A.M. Grishin, A mathematical modelling of forest fires and new methods of fighting them, Publishing House of the Tomsk University, Tomsk, 1996.

[16] J.L. Torero, A. Simeoni, Heat and mass transfer in fires: scaling laws, ignition of solid fuels and application to forest fires, Open Thermodyn. J. 4 (2010) 145155, doi:10.2174/1874396X01004010145.

[17] W.E. Mell, S.L. Manzello, A. Maranghides, D. Butry, R.G. Rehm, The wildland-urban interface fire problem - current approaches and research needs, Int. J. Wildland Fire 19 (2010) 238-251.

[18] A.P. Dimitrakopoulos, K.K. Papaioannou, Flammability assessment of mediterranean forest fuels, Fire Technol. 37 (2001) 143-152.

[19] C. Schemel, A. Simeoni, H. Biteau, J.D. Rivera, J.L. Torero, A calorimetric study of wildland fuels, Exp. Therm. Fluid Sci. 32 (2008) 1381-1389.

[20] P. Bartoli, A. Simeoni, H. Biteau, J.L. Torero, P.A. Santoni, Determination of the main parameters influencing forest fuel combustion dynamics, Fire Saf. J. 46 (2011) 27-33, doi:10.1016/j.firesaf.2010.05.002.

[21] P. Mindykowski, A. Fuentes, J.L. Consalvi, B. Porterie, Piloted ignition of wildland fuels, Fire Saf. J. 46 (2011) 34-40, doi:10.1016/j.firesaf.2010.09.003.

[22] B. Porterie, D. Morvan, J.C. Loraud, M. Larini, Firespread through fuel beds: modeling of wind-aided fires and induced hydrodynamics, Phys. Fluids 12 (2000) 1762-1782, doi:10.1063/1.870426.

[23] B. Porterie, J.L. Consalvi, A. Kaiss, J.C. Loraud, Predicting wildland fire behavior and emissions using a fine-scale physical model, Numer. Heat Transf., Part A: Appl. 47 (2005) 571-591, doi:10.1080/10407780590891362.

[24] D. Morvan, Numerical study of the behaviour of a surface fire propagating through a firebreak built in a mediterranean shrub layer, Fire Saf. J. 71 (2015) 34-48, doi:10.1016/j.firesaf.2014.11.012.

[25] D. Morvan, J.L. Dupuy, Modeling the propagation of a wildfire through a mediterranean shrub using a multiphase formulation, Combust. Flame 138 (2004) 199-210, doi:10.1016/j.combustflame.2004.05.001.

[26] S. Padhi, B. Shotorban, S. Mahalingam, Computational investigation of flame characteristics of a non-propagating shrub fire, Fire Saf. J. 81 (2016) 64-73, doi:10.1016/j.firesaf.2016.01.016.

[27] R. Shaw, U. Schumann, Large-eddy simulation of turbulent flow above and within a forest, Bound. Layer Meteorol. 61 (1992) 47-64.

[28] E.G. Patton, R.H. Shaw, M.J. Judd, M.R. Raupach, Large-eddy simulation of windbreak flow, Bound. Layer Meteorol. 87 (1998) 275-306.

[29] R.H. Shaw, E.G. Patton, Canopy element influences on resolved- and sub-grid-scale energy within a large-eddy simulation, Agric. Forest Meteorol. 115 (2003) 5-17.

[30] T. Watanabe, Large-eddy simulation of coherent turbulence structures associated with scalar ramps over plant canopies, Bound. Layer Meteorol. 112 (2004) 307-341.

[31] G.G. Katul, L. Mahrt, D. Poggi, C. Sanz, One and two-equation models for canopy turbulence, Bound. Layer Meteorol. 113 (2004) 81-109.

[32] H. Foudhil, Y. Brunet, J.P. Caltagirone, A fine-scale K-Epsilon model for atmospheric flow over heterogeneous landscaped, Environ. Fluid Mech. 5 (2005) 247-265.

[33] K. Gavrilov, D. Morvan, G. Accary, D. Lyubimov, S. Meradji, Numerical simulation of coherent turbulent structures and passive scalar dispersion in canopy sublayer, Comput. Fluids 78 (2013) 54-62.

[34] M. Larini, F. Giroud, B. Porterie, J.C. Loraud, A multiphase formulation for fire propagation in heterogeneous combustible media, Int. J. Heat Mass Transf. 41 (1998) 881-897.

[35] D. Morvan, J.L. Dupuy, E. Rigolot, J.C. Valette, FIRESTAR: a physically based model to study wildfire behaviour, Forest Ecol. Manag. 234 (2006) S114, doi:10. 1016/j.foreco.2006.08.155.

[36] W. Mell, A. Maranghides, R. McDermott, S.L. Manzello, Numerical simulation and experiments of burning douglas fir trees, Combust. Flame 156 (2009) 2023-2041, doi:10.1016/j.combustflame.2009.06.015. 
[37] J.L. Consalvi, F. Nmira, A. Fuentes, P. Mindykowski, B. Porterie, Numerical study of piloted ignition of forest fuel layer, Proc. Combust. Inst. 33 (2011) 2641-2648.

[38] F.P. Incropera, D.P. DeWitt, T.L. Bergman, A.S. Lavine, Fundamentals of heat and mass transfer, Wiley, 2007, doi:10.1016/j.applthermaleng.2011.03.022.

[39] C.M. Hoffman, J. Canfield, R.R. Linn, W. Mell, C.H. Sieg, F. Pimont, J. Ziegler, Evaluating crown fire rate of spread predictions from physics-based models, Fire Technol. 52 (2015) 221-237, doi:10.1007/s10694-015-0500-3.

[40] R.R. Linn, J. Reisner, J.J. Colman, J. Winterkamp, Studying wildfire behavior using FIRETEC, Int. J. Wildland Fire 11 (2002) 233, doi:10.1071/WF02007.

[41] Mell W. (2010) WFDS preliminary user's guide. http://www.fs.fed.us/pnw/fera/ research/wfds/wfds_user_guide.pdf.

[42] M.E. Alexander, M.G. Cruz, Evaluating a model for predicting active crown fire rate of spread using wildfire observations, Can. J. For. Res. 36 (2006) 30153028, doi:10.1139/x06-174.

[43] ISO-12136:2011 Reaction to fire tests - measurement of material properties using a fire propagation apparatus. International Organization for Standardization, Geneva, Switzerland.

[44] M. El Houssami, J.C. Thomas, A. Lamorlette, D. Morvan, M. Chaos, R. Hadden, A. Simeoni, Experimental and numerical studies characterizing the burning dynamics of wildland fuels, Combust. Flame 168 (2016) 113-126, doi:10.1016/j. combustflame.2016.04.004.

[45] X. Silvani, F. Morandini, Fire spread experiments in the field: temperature and heat fluxes measurements, Fire Saf. J. 44 (2009) 279-285.

[46] J.C. Thomas, A. Simeoni, M. Gallagher, N. Skowronski, An experimental study evaluating the burning dynamics of pitch pine needle beds using the FPA, Fire Saf. Sci. 11 (2014) 1406-1419, doi:10.3801/IAFSS.FSS.11-1406.

[47] R.M. Nelson, C.W. Adkins, Flame characteristics of wind-driven surface fires, Can. J. For. Res. 6 (1986) 1293-1300.

[48] W.M. Pitts, Wind effects on fires, Prog. Energy Combust. Sci. 17 (1991) 83-134

[49] K.L. Clark, N. Skowronski, M. Gallagher, Fire management and carbon sequestration in pine barren forests, J. Sustain. For. 34 (2015) 125-146, doi:10.1080/ 10549811.2014.973607.

[50] N. Ren, Y. Wang, S. Vilfayeau, A. Trouvé, Large eddy simulation of turbulent vertical wall fires supplied with gaseous fuel through porous burners, Combust. Flame 169 (2016) 194-208, doi:10.1016/j.combustflame.2015.12.008.

[51] D. Morvan, S. Méradji, G. Accary, Physical modelling of fire spread in grasslands, Fire Saf. J. 44 (2009) 50-61, doi:10.1016/j.firesaf.2008.03.004.

[52] S. Patankar, Numerical heat transfer and fluid flow, Academic press, 1980, pp. 1-197. Series in coputational methods in mechanics and thermal sciences.

[53] X. Zhou, S. Mahalingam, D. Weise, Modeling of marginal burning state of fire spread in live chaparral shrub fuel bed, Combust. Flame 143 (2005) 183-198, doi:10.1016/j.combustflame.2005.05.013.

[54] R. Clift, J. Grace, M.E. Weber, Bubbles, drops and particles, Academic Press, New York, 1978.

[55] N. Cheng, Calculation of drag coefficient for arrays of emergent circular cylinders with pseudofluid model, J. Hydraul. Eng. 139 (2013) 602-611, doi:10.1061/ (ASCE)HY.1943-7900.0000722.

[56] M.R. Raupach, Drag and drag partition on rough surfaces, Bound. Layer Meteorol. 60 (1992) 375-395, doi:10.1007/BF00155203.

[57] E. Mueller, LES modeling of flow through vegetation with applications to wildland fires, Worcester Polyticnic Institute, 2012.
[58] H.M. Nepf, J.A. Sullivan, R.A. Zavitoski, A model for diffusion within an emergent plant canopy, Limnol. Oceanogr. 42 (8) (1997) 85-95

59] A. Lamorlette, A. Collin, Analytical quantification of convective heat transfer inside vegetal structures, Int. J. Therm. Sci. 57 (2012) 78-84, doi:10.1016/j. ijthermalsci.2012.02.010.

60] T.F. Irvine, J.P. Hartnett, Advances in heat transfer, Academic Press, 1978.

[61] W.A. Khan, J.R. Culham, M.M. Yovanovich, Convection heat transfer from tube banks in crossflow: analytical approach, Int. J. Heat Mass Transf. 49 (2006) 4831-4838, doi:10.1016/j.ijheatmasstransfer.2006.05.042.

[62] T.J. Ohlemiller, Smoldering combustion, SFPE handbook of fire protection engineering, 3rd Ed, National Fire Protection Association, Quincy, MA, 2002 pp. 201-210. Chapter 2.

63] G. Rein, S. Cohen, A. Simeoni, Carbon emissions from smouldering peat in shallow and strong fronts, Proc. Combust. Inst. 32 (2009) 2489-2496, doi:10.1016/ j.proci.2008.07.008.

[64] D. Evans, H. Emmons, Combustion of wood charcoal, Fire Res. 1 (1977) 57-66

[65] A. Mendes, A. Dollet, C. Ablitzer, C. Perrais, G. Flamant, Numerical simulation of reactive transfers in spouted beds at high temperature: application to coal gasification, J. Anal. Appl. Pyrolysis 82 (2008) 117-128, doi:10.1016/j.jaap.2008. 02.001.

[66] D. Morvan, C. Hoffman, F. Rego, W. Mell, Numerical simulation of the interaction between two fire fronts in grassland and shrubland, Fire Saf. J. 46 (2011) 469-479, doi:10.1016/j.firesaf.2011.07.008.

[67] J.L. Dupuy, J. Maréchal, D. Morvan, Fires from a cylindrical forest fuel burner: combustion dynamics and flame properties, Combust. Flame 135 (2003) 6576, doi:10.1016/S0010-2180(03)00147-0.

[68] V. Tihay, A. Simeoni, P.-A. Santoni, L. Rossi, J.-P. Garo, J.-P. Vantelon, Experimental study of laminar flames obtained by the homogenization of three forest fuels, Int. J. Therm. Sci. 48 (2009) 488-501, doi:10.1016/j.ijthermalsci.2008. 03.018.

69] A. Simeoni, J.C. Thomas, P. Bartoli, P. Borowieck, P. Reszka, F Colella, P.A. Santoni, J.L. Torero, Flammability studies for wildland and wildland-urban interface fires applied to pine needles and solid polymers, Fire Saf. J. 54 (2012) 203-217, doi:10.1016/j.firesaf.2012.08.005.

[70] Z. Acem, A. Lamorlette, A. Collin, P. Boulet, Analytical determination and numerical computation of extinction coefficients for vegetation with given leaf distribution, Int. J. Therm. Sci. 48 (2009) 1501-1509, doi:10.1016/j.ijthermalsci. 2009.01.009.

[71] F.A. Albini, A model for fire spread in wildland fuels by radiation, Combust Sci. Technol. 42 (1985) 229-258.

[72] D. Morvan, M. Larini, Modeling of one dimensional fire spread in pine needles with opposing air flow, Combust. Sci. Technol. 164 (2001) 37-64, doi:10.1080 00102200108952161

[73] S. Vilfayeau, N. Ren, Y. Wang, A. Trouvé, Numerical simulation of underventilated liquid-fueled compartment fires with flame extinction and thermally-driven fuel evaporation, Proc. Combust. Inst. 35 (2015) 2563-2571 doi:10.1016/j.proci.2014.05.072.

[74] F.F.P. Kollman, W.A. Côté, Principles of wood science and technology, 1. Solid wood, Springer-Verlag Berlin Heidelberg, 1968, Principles of wood science and technology, doi:10.1007/978-3-642-87931-9. 